\title{
Epac2-Rap1 Signaling Regulates Reactive Oxygen Species Production and Susceptibility to Cardiac Arrhythmias
}

\author{
Zhaokang Yang, ${ }^{1, *}$ Hannah M. Kirton,, ${ }^{1, *}$ Moza Al-Owais, ${ }^{2, *}$ Jérôme Thireau, ${ }^{3}$ Sylvain Richard, ${ }^{3}$ \\ Chris Peers, and Derek S. Steele ${ }^{1}$
}

\begin{abstract}
Aims: In the heart, $\beta_{1}$-adrenergic signaling involves cyclic adenosine monophosphate (cAMP) acting via both protein kinase-A (PKA) and exchange protein directly activated by cAMP (Epac): a guanine nucleotide exchange factor for the small GTPase Rap1. Inhibition of Epac-Rap1 signaling has been proposed as a therapeutic strategy for both cancer and cardiovascular disease. However, previous work suggests that impaired Rap1 signaling may have detrimental effects on cardiac function. The aim of the present study was to investigate the influence of Epac2-Rap1 signaling on the heart using both in vivo and in vitro approaches.

Results: Inhibition of Epac2 signaling induced early afterdepolarization arrhythmias in ventricular myocytes. The underlying mechanism involved an increase in mitochondrial reactive oxygen species (ROS) and activation of the late sodium current $\left(\mathrm{INa}_{\text {late }}\right)$. Arrhythmias were blocked by inhibition of $\mathrm{INa}_{\text {late }}$ or the mitochondriatargeted antioxidant, mitoTEMPO. In vivo, inhibition of Epac2 caused ventricular tachycardia, torsades de pointes, and sudden death. The in vitro and in vivo effects of Epac2 inhibition were mimicked by inhibition of geranylgeranyltransferase-1, which blocks interaction of Rap1 with downstream targets.

Innovation: Our findings show for the first time that Rap1 acts as a negative regulator of mitochondrial ROS production in the heart and that impaired Epac2-Rap1 signaling causes arrhythmias due to ROS-dependent activation of $\mathrm{INa}_{\text {late }}$. This has implications for the use of chemotherapeutics that target Epac2-Rap1 signaling. However, selective inhibition of $\mathrm{INa}_{\text {late }}$ provides a promising strategy to prevent arrhythmias caused by impaired Epac2-Rap1 signaling.

Conclusion: Epac2-Rap1 signaling attenuates mitochondrial ROS production and reduces myocardial arrhythmia susceptibility. Antioxid. Redox Signal. 27, 117-132.
\end{abstract}

Keywords: Epac, Rap1, cardiac, arrhythmias, ROS, $\mathrm{Ca}^{2+}$

\section{Introduction}

YMPATHETIC CONTROL OF the myocardium makes a major contribution to the increase in cardiac output that occurs during exercise or stress. The inotropic and lusitropic effects of $\beta_{1}$-adrenergic $\left(\beta_{1}\right.$-AD) stimulation involve cyclic adeno- sine monophosphate (cAMP) acting via protein kinase-A (PKA) to increase phosphorylation of multiple intracellular targets, including the L-type calcium channel, phospholamban, troponin-I, myosin-binding protein-C, and the type- 2 ryanodine receptor (RyR2) (5). In addition, cAMP acts via exchange protein directly activated by cAMP (Epac): a

\footnotetext{
${ }^{1}$ Faculty of Biological Sciences, School of Biomedical Sciences, University of Leeds, Leeds, United Kingdom.

${ }^{2}$ Division of Cardiovascular Medicine, Faculty of Medicine and Health, University of Leeds, Leeds, United Kingdom.

${ }^{3}$ PHYMEDEXP, Physiologie et Médecine Expérimentale, Cœur et Muscles, INSERM U1046, CNRS UMR 9214, Université de Montpellier, Montpellier, France.

*These authors contributed equally to this work.

(C) Zhaokang Yang, et al., 2017; Published by Mary Ann Liebert, Inc. This is an Open Access article distributed under the terms of the Creative Commons Attribution License, which permits unrestricted use, distribution, and reproduction in any medium, provided the original work is properly cited.
} 


\section{Innovation}

Our findings show for the first time that activated Rap1 acts as a negative regulator of mitochondrial reactive oxygen species (ROS) production in the heart and that impaired Epac2-Rap1 signaling causes arrhythmias due to ROS-dependent activation of $\mathrm{INa}_{\text {late }}$. This has important implications for the use of chemotherapeutic agents that target Epac2-Rap1 signaling or pathological conditions where Rap1 signaling is impaired. However, we also show that inhibition of $\mathrm{INa}_{\text {late }}$ provides a promising strategy to prevent arrhythmias caused by impaired Epac2-Rap1 signaling. Coadministration of an $\mathrm{INa}_{\text {late }}$ inhibitor may allow therapeutic agents that target Epac2-Rap1 signaling to be tolerated without disturbances to cardiac rhythm.

guanine nucleotide exchange factor for the small GTPase Rap1, which increases the level of active Rap1GTP (25).

Prenylation (geranylgeranylation or farnesylation) of activated small GTPases is then necessary to permit interactions with target membranes (7). In the case of Rap1, prenylation involves geranylgeranylation via geranylgeranyltransferase-1 (GGT-1).

In ventricular myocytes, the Epac 1 isoform is present in the perinuclear region (33) and its activation induces nuclear $\mathrm{Ca}^{2+}$ signaling via a pathway involving phospholipase-C epsilon (PLC $\xi), \mathrm{Ca}^{2+} /$ calmodulin-dependent kinase II (CaMKII), and activation of inositol trisphosphate receptors, leading to a hypertrophic response mediated by HDAC5 and MEF2 (23$25,34)$. Epac2 exhibits a subsarcolemmal/t-tubule distribution and its activation contributes to a proarrhythmic increase in diastolic $\mathrm{Ca}^{2+}$ spark frequency that occurs during $\beta_{1}$-AD stimulation (33). The underlying signaling pathway involves PLC $\xi$, inositol trisphosphate receptor activation, and CaMKII-dependent phosphorylation of RyR2 (34).

Epac2-mediated arrhythmias are benign in the normal heart, but may become of significance in heart failure where sustained $\beta_{1}$-AD activation occurs (33). Under physiological conditions, the overall effect of simultaneous PKA and Epac2 activation may be Rap1-dependent facilitation of $\mathrm{Ca}^{2+}$-induced $\mathrm{Ca}^{2+}$ release $(27)$.

Inhibitors of Epac and GGT-1 are currently being investigated as therapeutics for both cancer and cardiovascular disease (32). Inhibition of either Epac or GGT-1 would be expected to reduce signaling via Rap1. However, limited evidence from previous studies suggests that impaired Rap1 signaling may adversely affect cardiac function, for example, GGT-1 inhibitors caused sudden death in mice; an effect that correlated with reduced Rap1 geranylgeranylation (21). In a clinical study, prolongation of the QT interval, arrhythmias, and syncope were reported in patients following administration of a combined GGT-1 and farnesyl transferase inhibitor (47). These findings are consistent with the phenotype of Rap1A knockout mice, which exhibit increased arrhythmia susceptibility (6).

Studies on other cell types have implicated Epac-Rap1 signaling in the control of reactive oxygen species (ROS) production, for example, Epac-Rap1 signaling suppressed ROS production in T lymphocytes and retinal pigment epithelium $(37,38,54)$. In kidney epithelial cells, Epac-Rap1 signaling inhibited superoxide production by mitochondria (46). As ROS are known to be involved in both physiological (30) and pathological (39) responses to $\beta_{1}$-AD stimulation and in susceptibility to arrhythmias (16), a regulatory influence of Epac-Rap1 signaling on ROS is likely to also be important in the myocardium, yet this is a largely unanswered question.

The aim of the present study was to investigate the role of Epac2-Rap1 signaling in the heart. Basal Rap1A activation was reduced by selective inhibition of Epac2 $(35,50)$ in adult rat ventricular myocytes (ARVMs). This was accompanied by early afterdepolarization arrhythmias (EADs), which occurred due to an increase in mitochondrial ROS production, activation of the late $\mathrm{Na}$ current $\left(\mathrm{INa}_{\text {late }}\right)$, and action potential (AP) prolongation. Both in vitro and in vivo, the proarrhythmic effects of Epac2 inhibition were recapitulated by inhibition of GGT-1 and therefore Rap1 signaling $(12,48)$. The EADs induced by Epac2 or GGT-1 inhibition were prevented by ranolazine, an inhibitor of $\mathrm{INa}_{\text {late }}$.

These findings show that Epac2-Rap1 is a negative regulator of mitochondrial ROS production in the heart, explain arrhythmias in patients receiving chemotherapeutics, which inhibit GGT-1, and offer a potential treatment with ranolazine.

\section{Results}

Inhibition of Epac2 induces EAD-like $\mathrm{Ca}^{2+}$ oscillations in ARVMs

ARVMs were loaded with fluo-4 and field stimulated at $0.1 \mathrm{~Hz}$ during confocal $\mathrm{Ca}^{2+}$ imaging in line-scan mode (Fig. 1A, upper). As shown in the associated line profiles, introduction of the selective Epac2 inhibitor, ESI-05 $(35,50)$, to the bathing solution was initially followed by slight prolongation of the early descending phase of the $\left[\mathrm{Ca}^{2+}\right]_{\mathrm{i}}$ transient (Fig. 1A, middle and lower). After 1-2 min, this prolongation developed into a distinct plateau phase comprising $\left[\mathrm{Ca}^{2+}\right]_{\mathrm{i}}$ oscillations; a characteristic of EAD arrhythmias. Resting $\left[\mathrm{Ca}^{2+}\right]_{\mathrm{i}}$ increased in the presence of ESI-05 and spontaneous $\mathrm{SR} \mathrm{Ca}^{2+}$ waves were often apparent between triggered events. Following introduction of ESI-05, EAD-like changes in the $\mathrm{Ca}^{2+}$ transient occurred in $66 \%$ of cells $(n=15$; Fig. 1B), but were absent from the control group $(n=30)$.

In the presence of $20 \mathrm{n} M$ isoproterenol (ISO), the percentage of cells affected by ESI-05 increased to $77.4 \%$ $(n=31)$. After preincubation with the CaMKII inhibitor, KN93, the percentage of cells affected by ESI-05 was markedly reduced to $21 \%(p<0.05, n=19)$, while the inactive control compound (KN92) had no significant effect ( $n=30, p>0.05$; Fig. 1B). Although not studied in detail, another Epac2 inhibitor (HJC0350) had effects on the electrically stimulated $\left[\mathrm{Ca}^{2+}\right]_{\mathrm{i}}$ transient that were comparable with those of ESI-05 (Supplementary Fig. S1; Supplementary Data are available online at www.liebertpub.com/ars).

As shown in Figure $1 \mathrm{C}$, the changes in resting and triggered $\mathrm{Ca}^{2+}$ release were accompanied by an increase in $\mathrm{Ca}^{2+}$ spark frequency of $64.3 \% \pm 14.8 \%(n=26, p<0.01)$. For detailed information on $\mathrm{Ca}^{2+}$ spark properties, see Supplementary Figure S2. The increase in $\mathrm{Ca}^{2+}$ spark frequency induced by ESI-05 was blocked by the CaMKII inhibitor, KN93, but not the inactive control compound, KN92 (Supplementary Fig. S3A). 

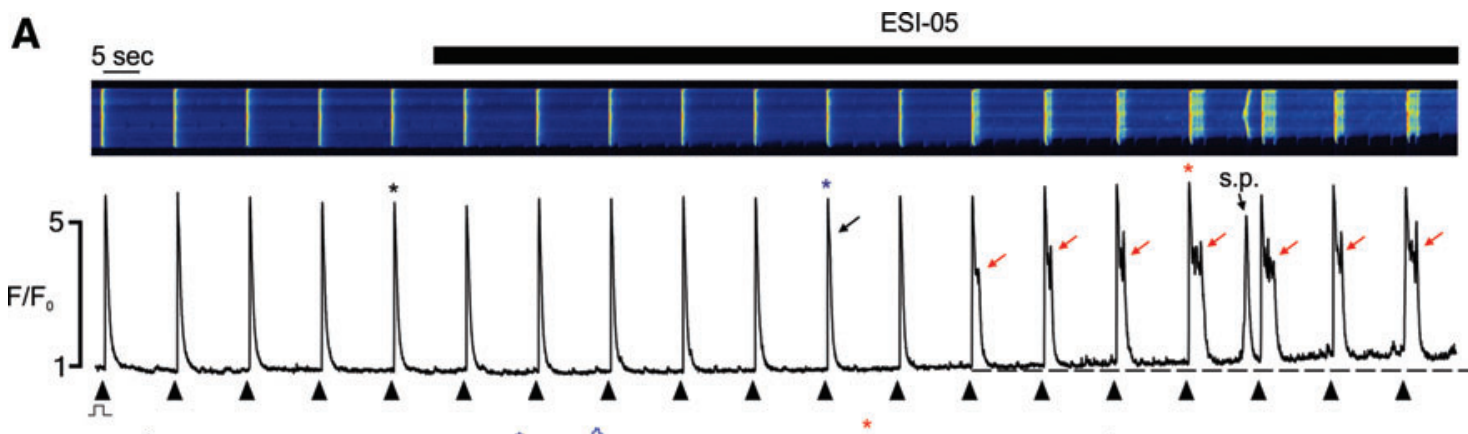
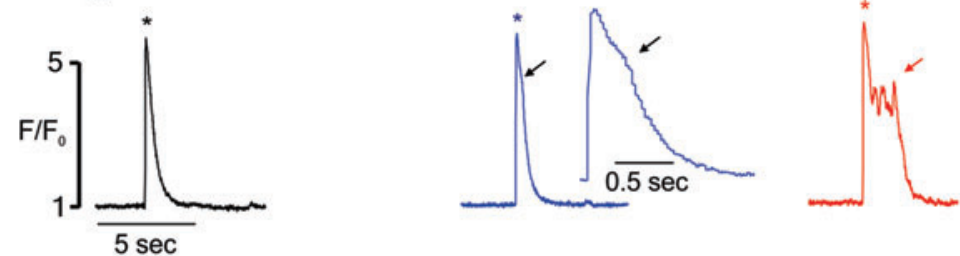

B
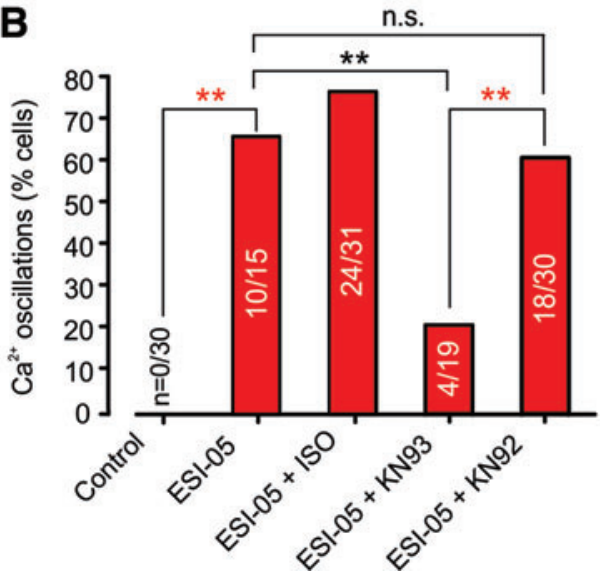

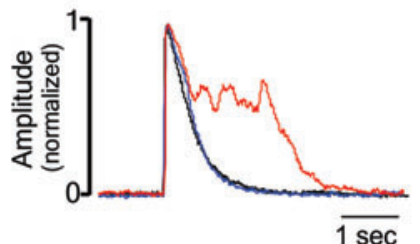

C

$$
\text { Control }
$$
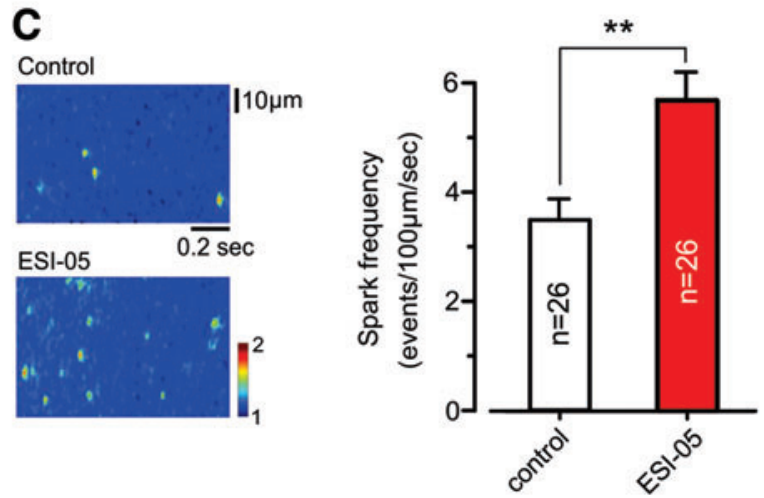

FIG. 1. Inhibition of Epac2 induces EAD-like $\left[\mathrm{Ca}^{2+}\right]$ oscillations. (A) Typical confocal line-scan recording from a field-stimulated ARVM loaded with fluo-4 (upper), the associated line profile (middle), and selected $\mathrm{Ca}^{2+}$ transients on an expended timescale, both individually and normalized/superimposed (lower). Introduction of ESI-05 $(25 \mu M)$ was followed by prolongation of the descending phase of the $\mathrm{Ca}^{2+}$ transient, which subsequently developed a distinct plateau phase with $\mathrm{Ca}^{2+}$ oscillations. s.p.: spontaneous SR Ca ${ }^{2+}$ release; black arrow: early prolongation of descending phase; red arrows: plateau/ $\mathrm{Ca}^{2+}$ oscillations. ' $*$ ' indicates corresponding $\mathrm{Ca}^{2+}$ transient. (B) Cumulative data showing the percentage of cells exhibiting EAD-like $\mathrm{Ca}^{2+}$ oscillations following addition of ESI-05 $(25 \mu M)$, ESI-05 + isoproterenol (ISO, $20 \mathrm{nM}$ ), ESI-05 + KN93 $(10 \mu M)$, and ESI-05 + KN92 $(10 \mu M)$. No cells exhibited EADs in the absence of ESI-05 ( $n=30)$. (C) Original (left) and cumulative data (right) showing the effects of ESI-05 $(25 \mu M)$ on the frequency of spontaneous $\mathrm{Ca}^{2+}$ sparks in ARVMs. ${ }^{* *} p<0.01$, n.s., not significant. ARVM, adult rat ventricular myocyte; EAD, early afterdepolarization arrhythmias; ISO, isoproterenol. To see this illustration in color, the reader is referred to the web version of this article at www.liebertpub.com/ars

\section{ESI-05 decreases Rap1GTP and its effects on $\left[\mathrm{Ca}^{2+}\right]_{i}$ are mimicked by Rap1 inhibition}

The effects of ESI-05 might reflect inhibition of Epac2 signaling and a consequent decrease in the active form of Rap1 (Rap1GTP). To investigate this possibility, a pull-down assay was used to measure Rap1GTP in ARVMs.

As shown in Figure 2A, active Rap1GTP was consistently detected in ARVMs under control conditions. This basal level of Rap1GTP was reduced $\sim 50 \%$ following inhibition of Epac2 with ESI-05 $(p<0.01, n=4)$. Conversely, Rap1GTP was significantly increased by the Epac activator, 8-CPT $(p<0.05, n=5)$, or by interventions that increase [cAMP] $]_{\mathrm{i}}$, including $\beta_{1}$-adrenoceptor $\left(\beta_{1}\right.$-ADR) activation with ISO alone $(p<0.01, n=5)$, or in combination with the phosphodiesterase inhibitor, rolipram $(p<0.005, n=7)$. These findings suggest that in common with PKA (31), Epac2 activation is significant under basal conditions in ARVMs. Basal Rap1 activation has also been reported in neonatal cardiac myocytes (45).

If the effects of ESI-05 are due to a decrease in Rap1GTP, then inhibition of Rap1 signaling should also be proarrhythmic. As illustrated in Figure 2B, previous work has shown that binding of active Rap1 with downstream targets requires its geranylgeranylation via GGT-1 and that selective inhibition of GGT-1 blocks Rap1-mediated effects $(12,48)$.

In the present study, introduction of the GGT-1 inhibitor, GGTI-298, recapitulated the effects of ESI-05, that is, GGTI-298 induced prolongation of the early descending phase of the $\left[\mathrm{Ca}^{2+}\right]_{i}$ transient, which then developed into a distinct plateau, with $\left[\mathrm{Ca}^{2+}\right]_{i}$ oscillations (Fig. 2C). As in Figure 1, the increase in $\mathrm{Ca}^{2+}$ spark frequency was a relatively early event, while the sustained increase in resting $\left[\mathrm{Ca}^{2+}\right.$ (signifying $\mathrm{Ca}^{2+}$ overload) typically occurred after the emergence of the sustained $\mathrm{Ca}^{2+}$ transients. Similar results were obtained in 8 of 10 cells exposed to GGTI-298. 
A

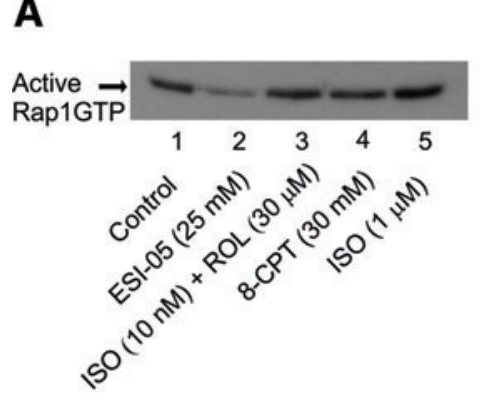

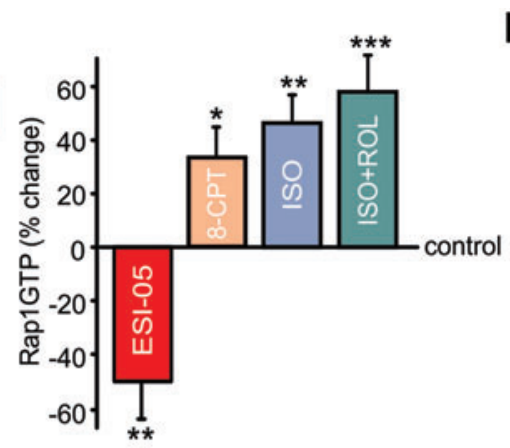
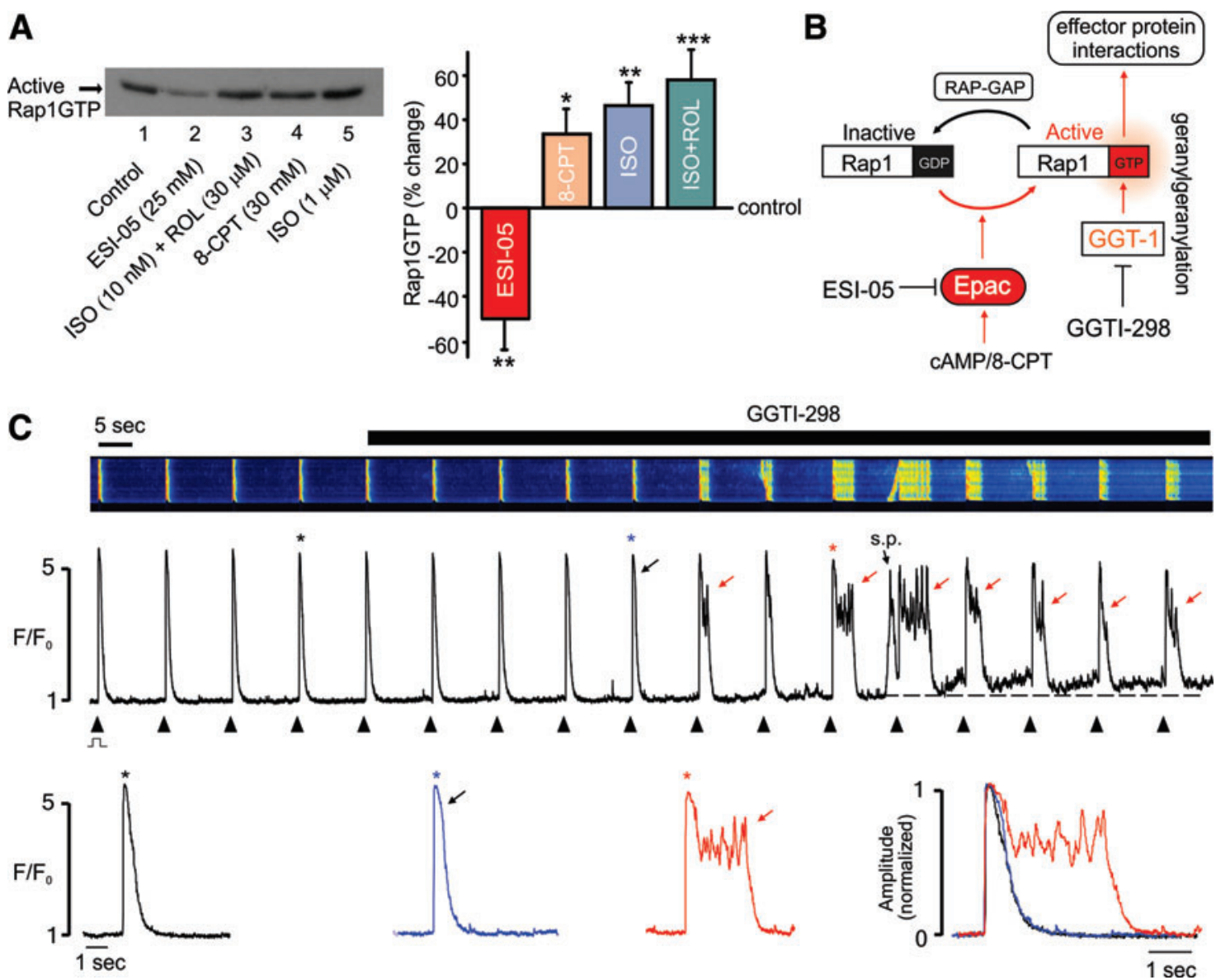

FIG. 2. Epac2 inhibition decreases basal Rap1GTP and the effects of ESI-05 are mimicked by Rap1GTP inhibition. (A) Original (left) and cumulative data (right) showing that Rap1GTP was detectable under basal conditions (see the Materials and Methods section) in ARVMS and could be reduced by Epac2 inhibition with ESI-05 or increased by the Epac activator 8-CPT $(25 \mu M)$, ISO $(1 \mu M)$, or a lower level of ISO $(10 \mathrm{n} M)$ in combination with the phosphodiesterase inhibitor, rolipram $(20 \mu M)$. ISO was added together with the $\beta_{2}$ antagonist CI 118,551 $(1 \mu M) . n=4-12, * p<0.05, * * p<0.01, * * * p<0.005$. (B) Schematic showing that Epac activation leads to increased levels of active Rap1GTP and that geranylgeranylation of Rap1GTP by GGT-1 facilitates membrane association and interactions with effector proteins. Inhibition of GGT-1 with GGTI-298 blocks the downstream effects of Rap1GTP. (C) Typical confocal line-scan recordings from a field-stimulated ARVM loaded with fluo-4 (upper), the associated line profile (middle), and selected $\mathrm{Ca}^{2+}$ transients presented on an expended timescale, both individually and normalized/superimposed (lower). Inhibition of GGT-1 with GGTI-298 $(0.1 \mu M)$ mimicked the effects of ESI-05 on $\left[\mathrm{Ca}^{2+}\right]_{\mathrm{i}}$ transients. s.p.: spontaneous SR $\mathrm{Ca}^{2+}$ release; black arrow: early prolongation of descending phase; red arrows: plateau/ $\mathrm{Ca}^{2+}$ oscillations. ' $*$ ' indicates corresponding $\mathrm{Ca}^{2+}$ transient. Similar effects occurred in 8 of 10 cells from three hearts. To see this illustration in color, the reader is referred to the web version of this article at www.liebertpub.com/ars

Although not studied in detail, another GGT-1 inhibitor (GGTI-2147) had effects on the electrically stimulated $\left[\mathrm{Ca}^{2+}\right]_{\mathrm{i}}$ transient that were comparable with those of GGTI298 (Supplementary Fig. S1). As with ESI-05, spontaneous $\mathrm{SR} \mathrm{Ca}^{2+}$ waves often occurred between triggered $\mathrm{Ca}^{2+}$ release events and resting $\left[\mathrm{Ca}^{2+}\right]_{\mathrm{i}}$, and $\mathrm{Ca}^{2+}$ spark frequency increased during exposure to GGTI-298 (Supplementary Fig. S2). The increase in $\mathrm{Ca}^{2+}$ spark frequency induced by GGTI-298 was also blocked by the CaMKII inhibitor, KN93, but not the inactive control compound, KN92 (Supplementary Fig. S3B).

\section{Inhibition of Epac2 or GGT-1 increases mitochondrial ROS production}

Experiments were carried out to investigate the mechanism underlying the changes in $\mathrm{Ca}^{2+}$ regulation induced by ESI- 05 or
GGTI-298. In other cell types, Rap1 signaling can modify ROS production via either NADPH oxidase (NOX) or mitochondria $(37,38,46,54)$. In the present study, preincubation with the NOX inhibitor, diphenyleneiodonium (DPI), failed to prevent the EAD-like $\mathrm{Ca}^{2+}$ oscillations induced by ESI-05 or GGTI298 (Fig. 3A, C). However, the reducing agent, dithiothreitol (DTT), the SOD mimetic, MnTMPyP, or the mitochondriatargeted ROS scavenger, mitoTEMPO, typically blocked the $\mathrm{Ca}^{2+}$ transient changes induced by both drugs.

Cumulative data summarizing the efficacy of various interventions to prevent the effects of ESI-05 or GGTI-298 are shown in Figure 3B and D. For both ESI-05 and GGTI-298, DPI had no significant effect, while DTT, MnTMPyP, and mitoTEMPO markedly reduced the percentage of cells that responded to the drugs. MitoTEMPO was consistently more effective than MnTMPyP, which might be explained if the primary action of ESI-05 and GGTI-298 is to increase mitochondrial superoxide 
A

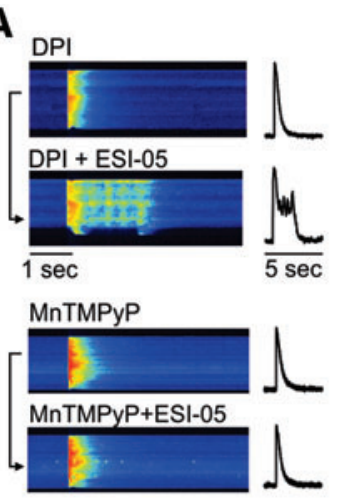

C DPI

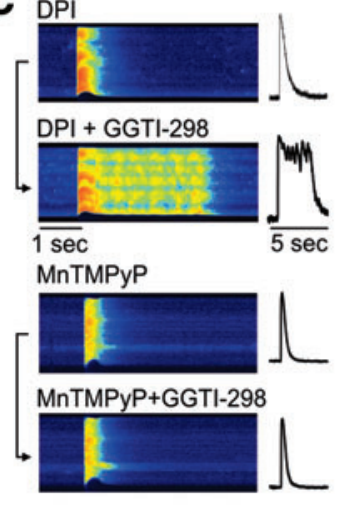

DTT

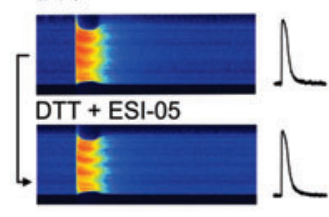

mitoTEMPO

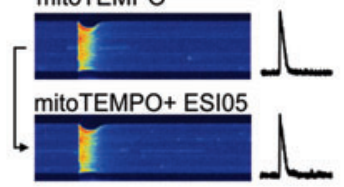

DTT

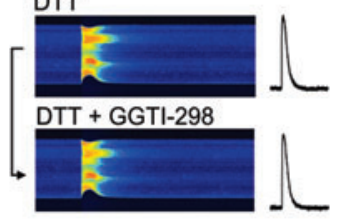

mitoTEMPO

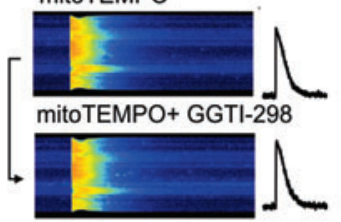

E

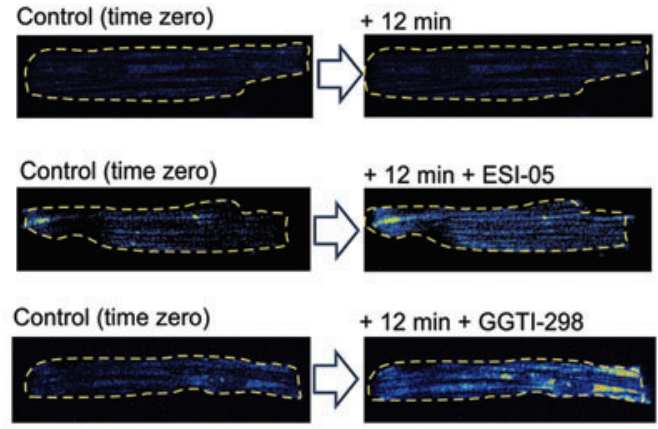

B

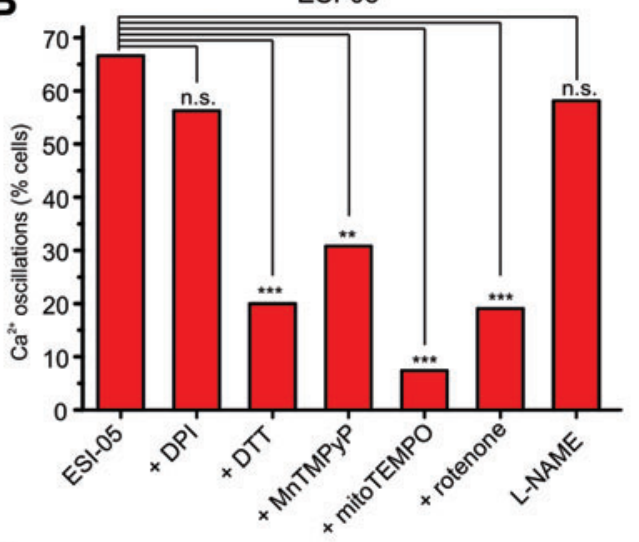

D

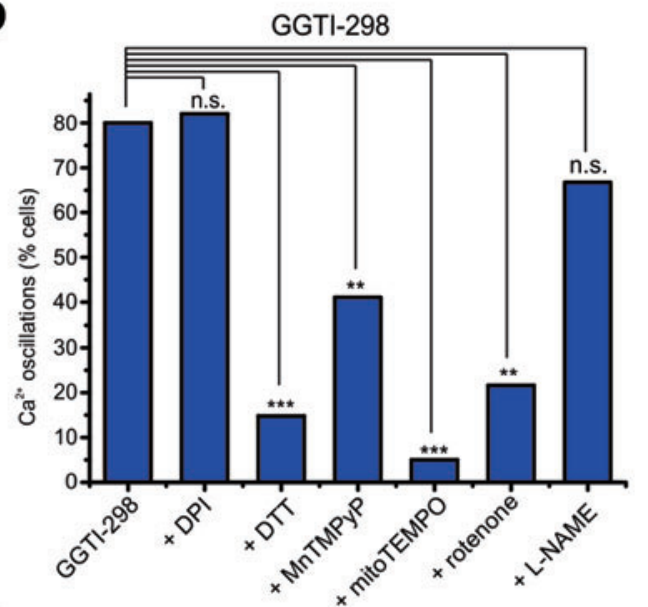

F

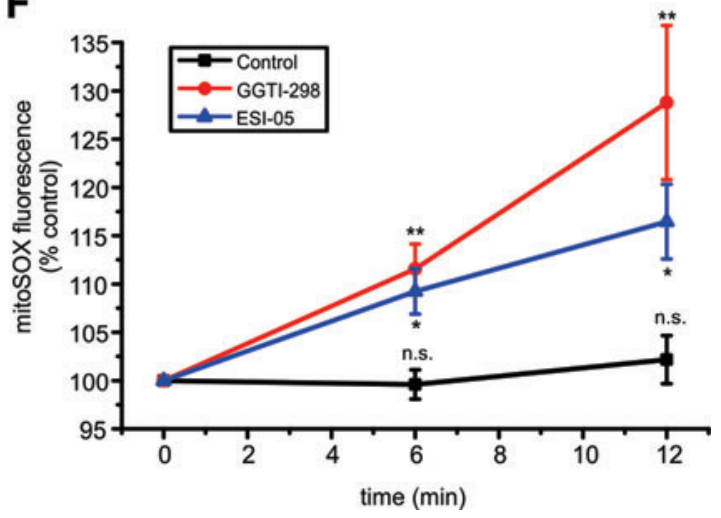

FIG. 3. Increased mitochondrial ROS production underlies effects of ESI-05 and GGTI-298. (A) Representative linescan images (left) and associated line profiles (right) obtained from field-stimulated ARVMs before (upper) and after (lower) introduction of ESI-05 (25 $\mu M)$ following preincubation with the NOX inhibitor, DPI $(20 \mu M)$, the reducing agent, dithiothreitol DTT $(2 \mathrm{mM})$, the SOD mimetic, MnTMPyP $(100 \mu M)$, or the mitochondria targeted antioxidant, mitoTEMPO $(30 \mu M)$. (B) Cumulative data showing the effects of all inhibitors tested on the percentage of cells exhibiting EAD-like $\left[\mathrm{Ca}^{2+}\right]$ oscillations, additionally including the mitochondrial inhibitor, rotenone $(100 \mathrm{nM})$, and the nitric oxide synthase inhibitor, L-NAME $(500 \mu M) . n=15-30$. (C, D) Show the same protocol and presentation of data for ARVMs exposed to GGT-298 $(0.1 \mu M) . n=10-27$. (E) Original xy confocal images showing mitoSOX fluorescence recorded at time zero and then after $12 \mathrm{~min}$, under control conditions $(n=15)$ (upper) or in the presence of ESI-05 ( $25 \mu M$, middle, $n=17)$ or GGTI$298(0.1 \mu M$, lower, $n=13)$. Yellow broken lines indicate cell outline. (F) Cumulative data showing the time-dependent change in mitoTEMPO fluorescence under control conditions or in the presence of ESI-05 or GGTI-298. $* p<0.05$, $* * p<0.01$, ***, $p<0.005$, n.s., not significant, $n=13-17$. DPI, diphenyleneiodonium; DTT, dithiothreitol; NOX, NADPH oxidase. To see this illustration in color, the reader is referred to the web version of this article at www.liebertpub.com/ars 
production. Consistent with this, the mitochondrial complex 1 inhibitor, rotenone, also markedly inhibited the effects of ESI05 and GGTI-298 (Fig. 3B, D). However, preincubation of cells with the nitric oxide synthase inhibitor, L-NAME, failed to prevent the effects of ESI-05 or GGTI-298 on $\left[\mathrm{Ca}^{2+}\right]_{\mathrm{i}}$, suggesting that increased NO or generation of peroxynitrite is unlikely to be involved.

Further experiments were carried out to detect changes in mitochondrial superoxide production using mitoSOX. Figure 3E (left) shows original data obtained under control conditions and in the presence of ESI-05 or GGTI-298. With both drugs, mitoSOX fluorescence increased over a period of 12-min exposure, while there was no apparent change in the control response over the same time period. The cumulative data (Fig. 3F) show that with ESI-05 $(n=17)$ or GGTI-298 $(n=13)$, mitoSOX fluorescence was significantly greater than control at both 6- and 12-min time points $(p<0.05, n=13$ 17). Under control conditions, in the absence of the drugs, mitoSOX fluorescence did not increase significantly over the same time period ( $p>0.05, n=15)$. Increases in cellular ROS with both ESI-05 and GGTI-298 were also detected using CM- $\mathrm{H}_{2}$ DCFDA fluorescence (Supplementary Fig. S4).

Adenoviral expression of roGFP (24-h culture) was used to detect possible changes in the glutathione redox potential within myocytes. As shown in Supplementary Figure S5A, mito-roGFP produced a blocky fluorescence pattern, which is consistent with mitochondrial localization (15). Exposures less than $15 \mathrm{~min}$ had no significant effect on mito-roGFP fluorescence (not shown). However, as shown in Supplementary Figure 5B and C, 30-min exposure to GGTI-298 resulted in a small but significant decrease in the mito-roGFP2 signal (488-nm excitation), which is consistent with a rise in ROS production.

One technical consideration was that during prolonged (20$30 \mathrm{~min})$ drug exposures, cells often became spontaneously active, presumably due to $\mathrm{Ca}^{2+}$ overload (e.g., Fig. 1A), which could change the confocal plane, leading to a relatively large variability in the measured response. Consequently, we undertook further experiments to measure the GSH/GSSG ratio in aliquots of cells using a luminescence-based system (GSH/ GSSG-Glo) to quantify cellular GSH/GSSG ratios in ventricular cardiac cells. As shown in Supplementary Figure S5C, both drugs caused a significant reduction in the GSH/GSSG ratio measured using this method.

Adenoviral expression of the mitochondrial $\mathrm{Ca}^{2+}$ sensor mitycam (15) again exhibited an expression pattern consistent with mitochondrial localization. Exposure to either ESI05 or GGTI for $20 \mathrm{~min}$ resulted in a slight decrease in the mean fluorescence level (consistent with an increase in $\left[\mathrm{Ca}^{2+}\right]$, although this was not statistically significant, Supplementary Figure S6A).

In experiments on HEK-293 cells, it was found that partial ( $\sim 50 \%$ ) siRNA knockdown of Rap1 increased basal ROS production. Thereafter, against this background of reduced Rap1 signaling, subsequent inhibition of Epac2 caused a proportionately greater increase in $\mathrm{CM}-\mathrm{H}_{2} \mathrm{DCFDA}$ fluorescence (Supplementary Fig. S7).

\section{Electrophysiological consequences of Epac-Rap1 signaling inhibition}

Experiments were carried out to investigate the effects of ESI-05 and GGTI-298 on AP duration and INa. In whole-cell patch-clamp experiments, oscillatory EADs were induced by ESI-05 during repetitive pacing when the drug was present both in the patch pipette and in the bathing solution (Fig. 4A). Similar results were obtained with GGTI-298 in the bathing solution and the membrane-impermeant product of the prodrug (GGTI-297) in the patch pipette (not shown). EADs were typically absent when the drugs were omitted from the patch pipette, which likely reflects cell dialysis, such that the cytosolic concentration is lower than that of the external solution.

In experiments to identify effects on AP duration, ESI-05 and GGTI-298 were only added to bathing solution, which allowed effects to be determined before and then after addition of the drugs in each cell. As shown in Figure 4B and C, both ESI-05 and GGTI-298 consistently increased AP duration. One possible explanation for prolongation of the AP is increased activation of $\mathrm{INa}_{\text {late }}$, which has been reported to occur with other interventions that increase mitochondrial ROS (62). Consistent with this possibility, preincubation of cells with the $\mathrm{INa}_{\text {late }}$ inhibitor, ranolazine $(20 \mu M)$, prevented lengthening of the AP with either ESI-05 or GGTI-298 (Fig. 4D, E). Furthermore, as in experiments involving $\left[\mathrm{Ca}^{2+}\right]_{\mathrm{i}}$ measurement alone (Fig. 3), preincubation with mitoTEMPO also prevented the effects of both drugs on AP duration (Fig. 4D, E).

Voltage-clamp experiments were conducted to investigate modulation of INa by ESI-05 and GGTI-298 (Fig. 5). Both agents had a modest inhibitory effect on the peak INa (e.g., Fig. 5A left). It should be noted that with series resistance compensation of 60-80\%, peak Na current amplitude values are likely to incur a modest systematic error, but this does not affect our overall conclusion. Much more striking was the increase in $\mathrm{INa}_{\text {late }}$ (Fig. 5A middle and right). Consistent with the idea that increased $\mathrm{INa}_{\text {late }}$ accounts for the proarrhythmic actions of these drugs, augmentation of $\mathrm{INa}_{\text {late }}$ (but not the inhibition of peak INa) was inhibited by ranolazine and mitoTEMPO (Fig. 5A middle and right); mean data for these effects are shown in Figure 5B (ESI-05) and 5C (GGTI-298).

Further experiments were done to investigate the possibility that ESI-05 or GGTI-298 may influence EAD susceptibility by affecting the L-type $\mathrm{Ca}^{2+}$ current (ICa). However, as shown in the original data (Fig. 6A) and summarized in Figure 6B, neither ESI-05 nor GGTI-298 had a significant effect on the time course or amplitude of ICa in ventricular myocytes.

\section{In vivo effects of ESI-05 and GGTI-298}

To investigate the effects of ESI-05 and GGTI-298 in vivo, drugs were introduced following administration of ISO ( $1 \mathrm{mg} / \mathrm{kg}$ ip) to induce submaximal $\beta_{1}$-AD stimulation, which would be expected to increase the proarrhythmic effect of both drugs (Fig. 1B). ISO induced a significant increase in heart rate in all groups $(p<0.001 v s$. baseline) (Fig. 7A). However, the heart rate was not different between the 3 groups under baseline conditions, after ISO, or after either ESI-05 or GGTI-298. During vehicle $\mathrm{NaCl}$, ESI-05, and GGTI-298 (all with DMSO, 1/1000: v/v), heart rate increased further and to a similar extent $(p<0.01$, Fig. 7A). No difference was observed between the ESI-05 and GGTI-298 groups for heart rate.

Interestingly, ESI-05 or GGTI-298 induced a large increase in the occurrence of ventricular extrasystoles when compared with vehicle $(p<0.01$, Fig. 7B). These arrhythmias occurred preferentially in the repolarization phase of the 

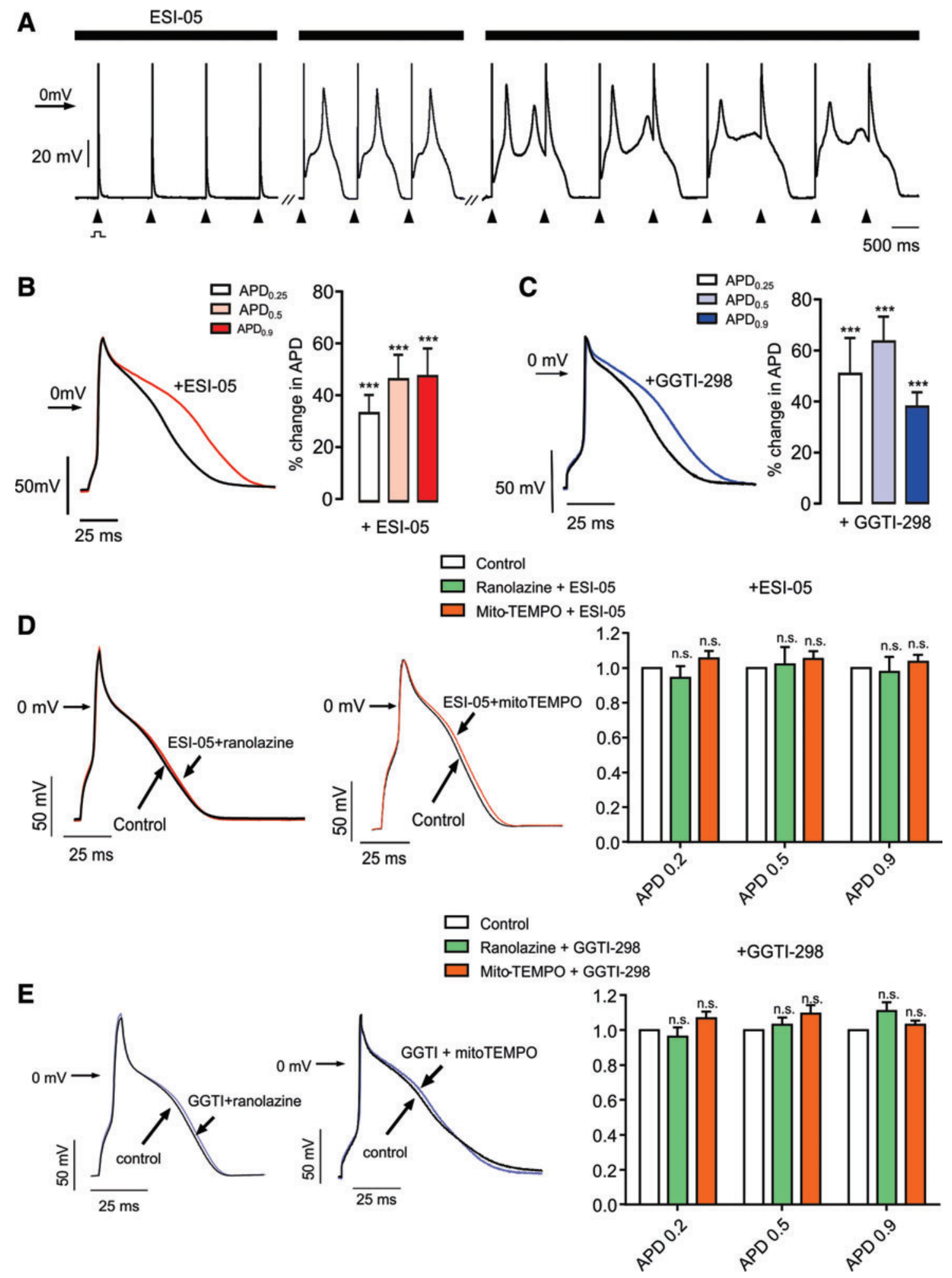

FIG. 4. Effects of ESI-05 or GGTI-298 on AP duration. (A) Whole-cell patch-clamp recording of APs obtained from an ARVM stimulated repetitively (arrows) at $1 \mathrm{~Hz}$. During exposure to ESI-05, the descending phase of the AP developed a sustained plateau with oscillations in $\mathrm{E}_{\mathrm{m}}$, characteristic of EADs. Breaks (-//-) indicate 2 and 4 min after initiation of recording. (B) Original (left) and cumulative data (right) showing AP prolongation in the presence of ESI-05 $(n=9)$. $(\mathbf{C})$ Original (left) and cumulative data (right) showing AP prolongation in the presence of GGTI-298 $(n=13)$. (D) Original (left) and cumulative data (right) showing that preincubation of cells with either mitoTEMPO $(30 \mu M, n=6)$ or ranolazine $(20 \mu M, n=5)$ prevented the increase in AP duration with ESI-05. (E) Original (left) and cumulative data (right) showing that preincubation of cells with either mitoTEMPO $(30 \mu M, n=5)$ or ranolazine $(20 \mu M, n=5)$ prevented the increase in AP duration with GGTI-298. n.s., no significant difference. $* * * p<0.001$. AP, action potential. To see this illustration in color, the reader is referred to the web version of this article at www.liebertpub.com/ars 
A

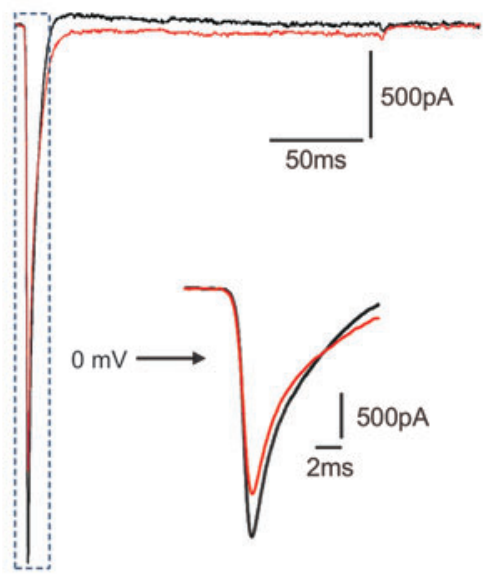

B

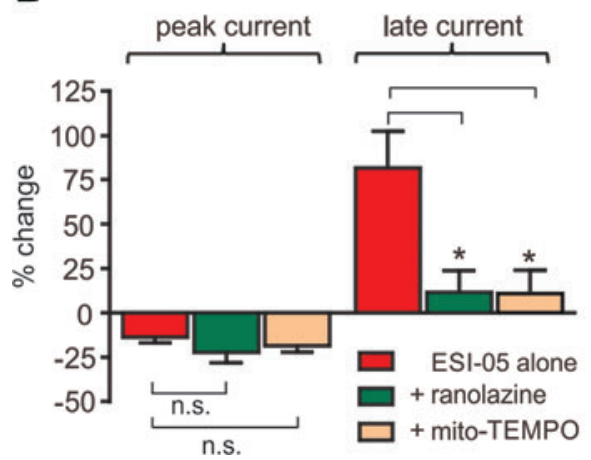

ESH05

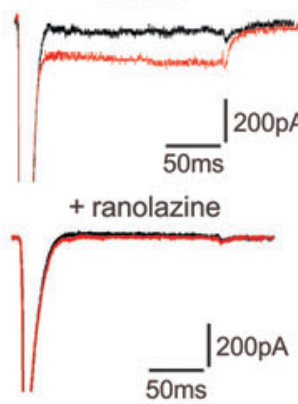

+mito-TEMPO

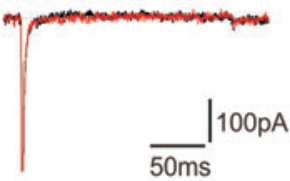

GGTI-298
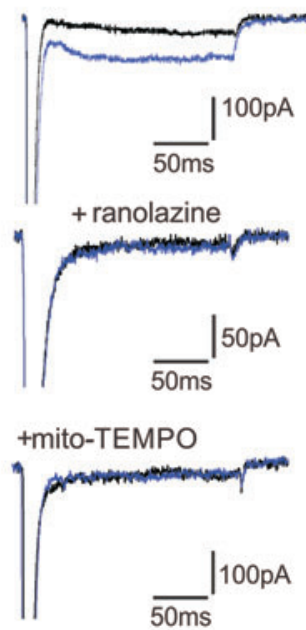

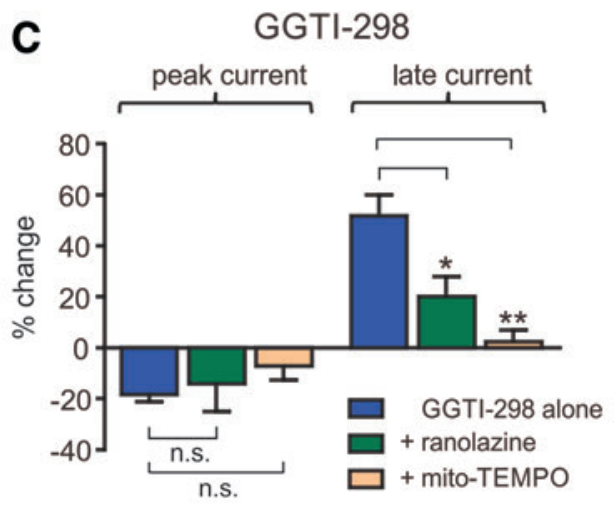

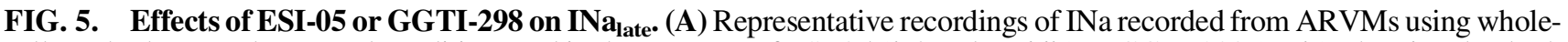
cell patch-clamp under control conditions and in the presence of ESI-05 (left and middle) or GGTI-298 (right), showing that both drugs increase $\mathrm{INa}_{\text {ate }}$. The effects of ESI-05 or GGTI-298 on $\mathrm{INa}_{\text {late }}$ were markedly reduced by preincubation of ARVMs with

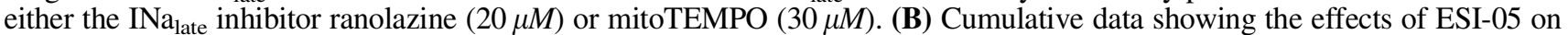
$\mathrm{INa}_{\text {late }}$ and the effects of preincubation with ranolazine or mitoTEMPO $(n=5-7)$. (C) Cumulative data showing the effects of GGTI-298 on INa $\mathrm{Iate}_{\text {and }}$ ane effects of preincubation with ranolazine or mitoTEMPO. $n=5-12, * p<0.05$, $* * p<0.01$, n.s., not significant. To see this illustration in color, the reader is referred to the web version of this article at www.liebertpub.com/ars

electrocardiogram (ECG) (into end-T wave). A typical example of such arrhythmias after ESI-05 injection is shown in Figure 7C.

No difference was noted between ESI-05 and GGTI-298 groups for the occurrence of ventricular extrasystoles. In addition, both ESI-05 and GGTI-298 triggered sustained ventricular tachycardia in four of seven animals and in three of five animals, respectively, whereas no animals exhibited triggered ventricular tachycardia in the vehicle-treated group ( $p<0.05$ for ESI-05 and GGTI-298 vs. vehicle, Fisher's exact test). Among these animals, one and two rats exhibited torsades de pointes in the ESI-05 and GGTI-298 groups, respectively, which degenerated into sudden cardiac death (Fig. 7D). Ultimately, four of seven rats died within $24 \mathrm{~h}$ following ESI-05 injection, of which two were the result of documented ventricular tachycardia and cardiac arrest within the first $180 \mathrm{~min}$ after injection, and two of five died after injection of GGTI-298, with documented torsades de pointes.

\section{Discussion}

Sympathetic adrenergic drive to the heart is fundamental to the control of cardiac output during stress or exercise. While the role of cAMP acting via PKA has been characterized in detail, the identification of Epac-mediated effects has been hampered by a lack of selective inhibitors. However, several Epac inhibitors have recently been identified (50) and independent analysis confirmed ESI-05 as a selective inhibitor of Epac2, capable of blocking its action as a guanine nucleotide exchange factor for Rap1 (35). In this study, ESI-05 was used to induce acute inhibition of Epac2, thereby revealing the influence of this pathway on cardiac cell function. As summarized in Figure 8, the findings suggest that Epac2-Rap1 signaling exerts a tonic inhibitory influence on mitochondrial ROS production, without which myocytes exhibit increased in vivo and in vitro susceptibility to arrhythmias and abnormal $\mathrm{Ca}^{2+}$ cycling.

\section{The effects of Epac2 inhibition are caused by mitochondrial ROS}

The EADs induced by Epac2 inhibition occur via a mechanism that involves an increase in cellular ROS, CaMKII activation, an increase in $\mathrm{INa}_{\text {late }}$, and AP prolongation (Figs. 1b, $3 \mathrm{e}, 4 \mathrm{~b}$, and 5a). This has similarities to angiotensin-II-induced EAD arrhythmias, which have also been linked to an increase in superoxide production and CaMKII activation (62). In this 


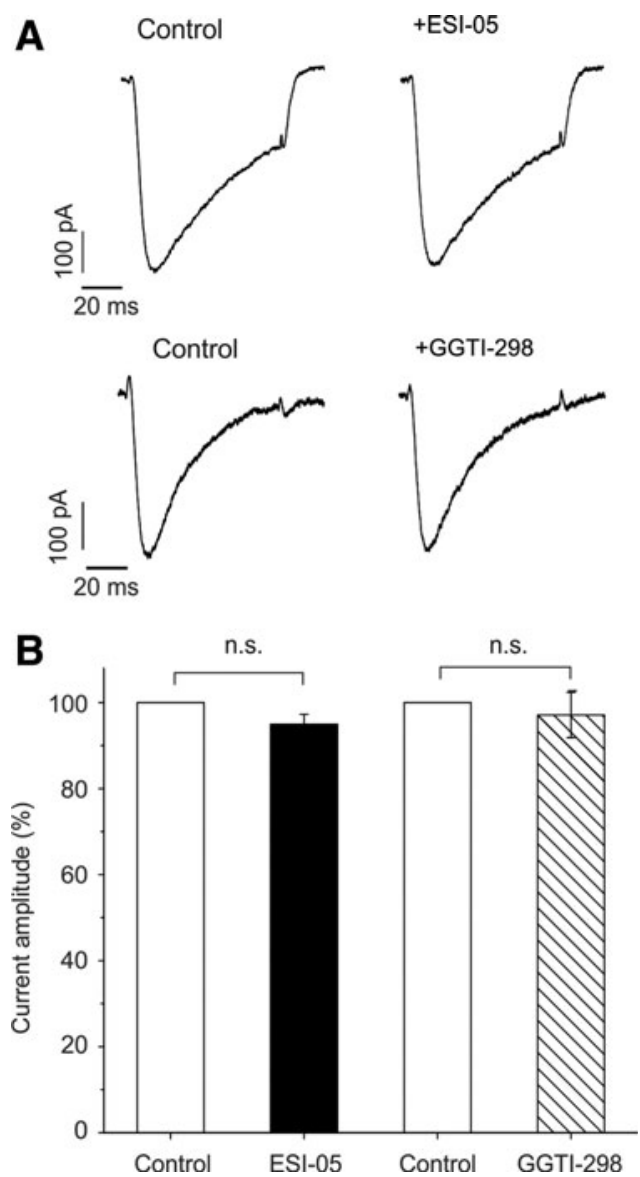

FIG. 6. Inhibition of Epac-Rap1 signaling does not affect ICa. (A) $\mathrm{L}$-type $\mathrm{Ca}^{2+}$ currents were evoked in isolated rat ventricular myocytes before and during exposure of ESI05 (upper) or GGTI-298 (lower). Cells were exposed to either drug for $3.3 \mathrm{~min}$. Currents were evoked by step depolarizations from -30 to $+10 \mathrm{mV}(75 \mathrm{~ms}, 0.1 \mathrm{~Hz})$. (B) Bar graph showing cumulative data (mean \pm SE) with the amplitude expressed as a percentage of the control current amplitude. Neither ESI-05 ( $p>0.05, n=5)$ nor GGTI-298 $(p>0.05, n=5)$ resulted in a significant change in peak ICa. Data were obtained from three hearts.

study, the underlying mechanism is known to involve oxidative activation of CaMKII, which leads to phosphorylation of RyR2 (e.g., at 2814) and Nav1.5 (e.g., at S571), thereby increasing the RyR2-mediated SR $\mathrm{Ca}^{2+}$ leak and $\mathrm{INa}_{\text {late }}(40)$.

The close proximity of subsarcolemmal and myofibrillar mitochondria to the superficial surface membrane and the ttubules means that the organelles are ideally placed to influence the function of RyR2 within the junctional SR and sarcolemmal ion channels (41). However, the angiotensin II-mediated increase in ROS is inhibited by DPI and absent in cells lacking functional NOX2 (53), suggesting a primary action via NOX, which then stimulates mitochondrial ROS production, that is, ROS-induced ROS release $(9,53)$. In the present study, the lack of effect of DPI suggests that NOX is not the primary source of ROS when Epac2 is inhibited (Fig. 3). Instead, the increase in mitoSOX fluorescence following Epac2 inhibition, the ability of mitoTEMPO to antagonize ESI-05-induced arrhythmias, and the inhibitory effect of rotenone implicate superoxide originating from the mitochondria.
These findings are consistent with recent work on other cell types, which suggest that Epac-Rap1 signaling can regulate mitochondrial ROS $(37,38,46,54,57)$, for example, hyperglycemia inhibits Rap1 expression and activity, leading to renal tubular cell injury in patients with diabetic neuropathy and STZ-induced diabetic animal models, via a mechanism that involves overproduction of mitochondrial ROS (57).

It has been reported previously that Rap1 and other small GTP-binding proteins can interact with mitochondria $(17,49$, 52 ) and, in some cases, modify the structure or function of the organelle (1). Alternatively, Rap1GTP might act indirectly via associated pathways such as PI3K (37) or PLC $\xi / \mathrm{PKC}$ (26). The identification of a link between Epac-Rap1 signaling and ROS production is also relevant to emerging evidence that cAMP can act via PKA to influence mitochondrial function $(8,10,42,52)$.

\section{The effects of Epac-2 inhibition are mimicked by inhibition of GGT-1}

Rap1 prenylation occurs exclusively via geranylgeranylation (7) and previous work has shown that GGTI-298 and related drugs selectively inhibit GGT-1 and the effects of Rap1GTP on downstream targets, without affecting protein farnesylation $(12,48)$.

In the present study, for all parameters measured at the cellular level, GGTI-298 produced effects that were strikingly similar to those of Epac2 inhibition, including an increase in mitochondrial ROS production, an increase in $\mathrm{INa}_{\text {late }}$, AP prolongation, and EADs (Figs. 3, 4, and 5). In vivo, the proarrhythmic effects of ESI-05 and GGTI-298 were also remarkably similar (Fig. 7). The similar effects of Epac2 and GGT-1 inhibition are consistent with inhibitory actions at different points on the Epac-Rap1 signaling pathway (Figs. 2B and 8).

\section{Physiological and pathological significance of Epac2 ROS regulation}

During $\beta_{1}$-AD stimulation, PKA-mediated effects on mitochondria promote superoxide production and the resultant modulation of ion channel function contributes to the increase in $\mathrm{SR} \mathrm{Ca}^{2+}$ release and contractile force under physiological conditions (3). However, excessive ROS generation is detrimental to cell function and, beyond a critical point, ROS release is irreversible and self-sustaining (63). The present study suggests that in the heart, when [cAMP] and PKA activation increases during $\beta_{1}$ - $\mathrm{AD}$ stimulation, concomitant activation of Epac2 provides negative feedback, which attenuates mitochondrial ROS generation. When this mechanism is acutely interrupted by Epac2 or GGT1 inhibition, the consequence is increased ROS production (Fig. 3) and EAD arrhythmias (Figs. 1-4), the incidence of which is increased by $\beta_{1}$-ADR stimulation (Fig. 1B).

Previous work has shown that heart failure is associated with reduced expression of enzymes that initiate degradation of cAMP, including phosphodiesterase $(13,19,20,29)$, predisposing to an increase in PKA-mediated phosphorylation of some target proteins (e.g., RyR2), despite downregulation of $\beta_{1}$-ADR $(11,19,36,59)$. Depending on the model, Epac2 mRNA expression is unchanged or may decrease in heart failure $(24,51)$, while PKA expression and activity remain constant or increase $(14,18,55)$.

Based on the present findings, the development of an imbalance between PKA and Epac branches of the cAMP 

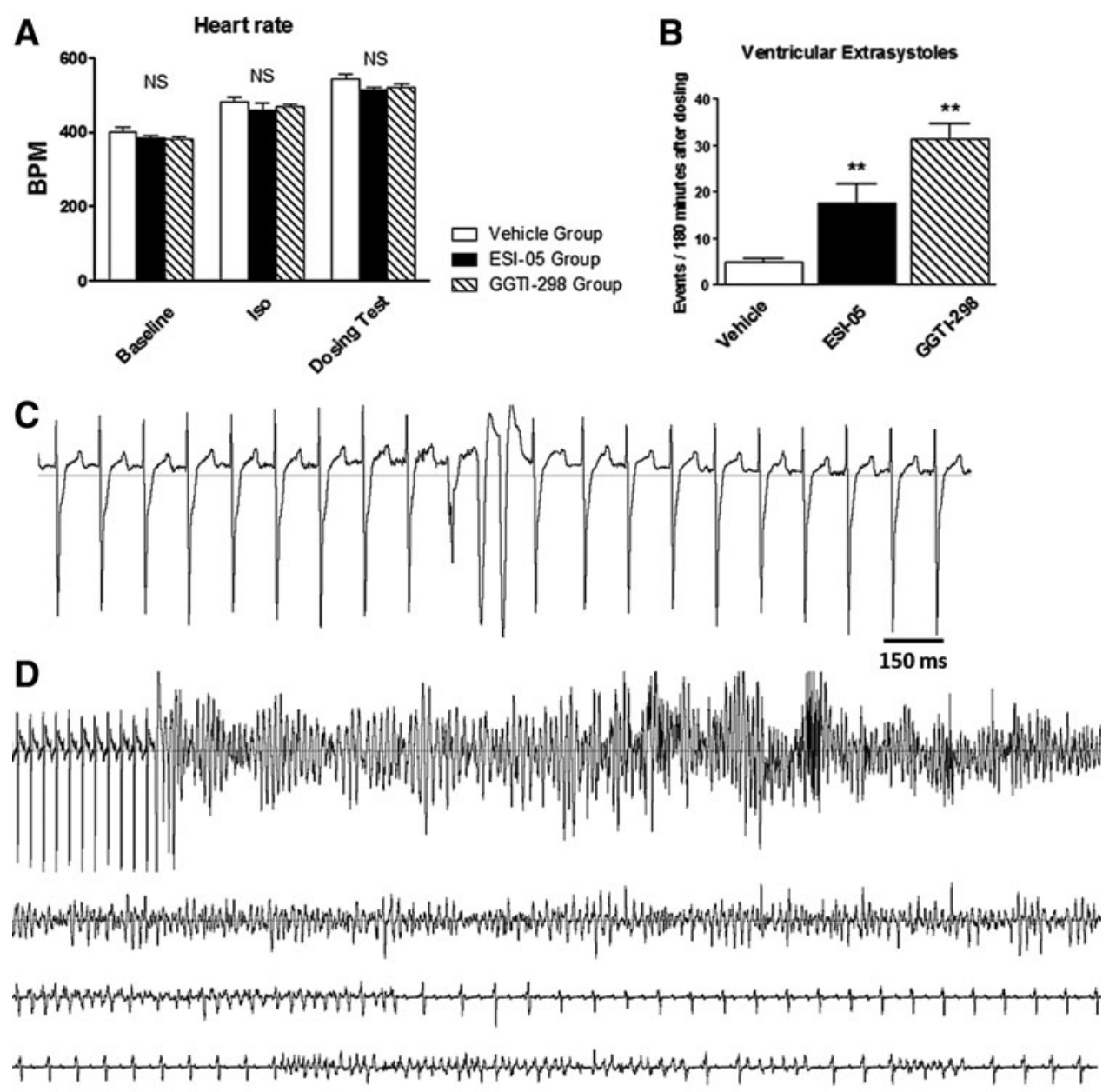

\section{$5 \overline{500 \mathrm{~ms}}$}

FIG. 7. In vivo effects of ESI-05 and GGTI-298. (A) Mean heart rate calculated in vehicle $(n=7)$, ESI-05 $(n=7)$, and GGTI-298 groups $(n=5)$ in baseline conditions, after isoproterenol injection $(1 \mathrm{mg} / \mathrm{kg}$ ip., in sterile $\mathrm{NaCl} 0.9 \%$ vehicle $)$, and after vehicle (DMSO/NaCl solution ip., 1/1000: v/v), ESI-05 (1 mg/kg ip., in DMSO/NaCl solution, 1/1000: v/v), or GGTI298 (1 mg/kg ip., in DMSO/NaCl solution, 1/1000: v/v). (B) Ventricular extrasystoles were counted over $180 \mathrm{~min}$ from ECGs after vehicle (DMSO/NaCl solution ip., 1/1000: v/v), ESI-05 (1 mg/kg ip., in DMSO/NaCl solution, $1 / 1000: \mathrm{v} / \mathrm{v})$, or GGTI-298 (1 mg/kg ip., in DMSO/NaCl solution, 1/1000: v/v). (C) Typical example of ventricular extrasystoles recorded after ESI-05 injection. (D) Typical example of torsades de pointes initiated by a ventricular extrasystole and terminated in sudden cardiac death recorded after ESI-05 injection. NS, no significant difference. ** $p<0.01$ versus vehicle, Student's $t$ test. $n=5-12, * p<0.05, * * p<0.01$.

signaling pathway would be expected to cause increased mitochondrial ROS production and predisposition to EAD arrhythmias, both of which are features of heart failure (58). However, the effects of acute pharmacological inhibition of Epac-Rap1 signaling may have more pronounced effects than slower changes in protein expression, where compensatory adaptations may occur. In addition, the effects of an acute increase in ROS production in an otherwise normal heart may differ from the tonic effect of chronically elevated ROS in disease states (e.g., diabetes or heart failure) where major functional and structural adaptations develop over a prolonged period.

Transgenic knockout models of Epac1/2 or Rap1A might provide information regarding the long-term effects of reduced signaling via Epac2-Rap1. A recent patent described long-QT and increased arrhythmia susceptibility at rest and in response to ISO in a Rap1A knockout mouse (6). The phenotype is qualitatively consistent with the results of the present study, including the finding that arrhythmias were linked to abnormal Nav1.5 function.

In contrast, two independent Epac2 knockout models did not exhibit increased susceptibility to arrhythmias at rest or during $\beta$-adrenergic stimulation $(28,33)$. This might be explained by adaptive changes in other pathways, which maintain an adequate level of Rap1GTP, or possibly a compensatory increase in antioxidant capacity. However, some caution is appropriate in interpreting the findings from existing Epac1/2 mouse studies because the phenotypes of the two models differ so markedly; in one model, Epac2 was solely responsible for the RyR2mediated increase in $\mathrm{Ca}^{2+}$ spark frequency during $\beta_{1}$-adrenergic stimulation and Epac1 was localized to the nucleus (33). In the other, Epac1 had major effects on both phospholamban/SERCA 


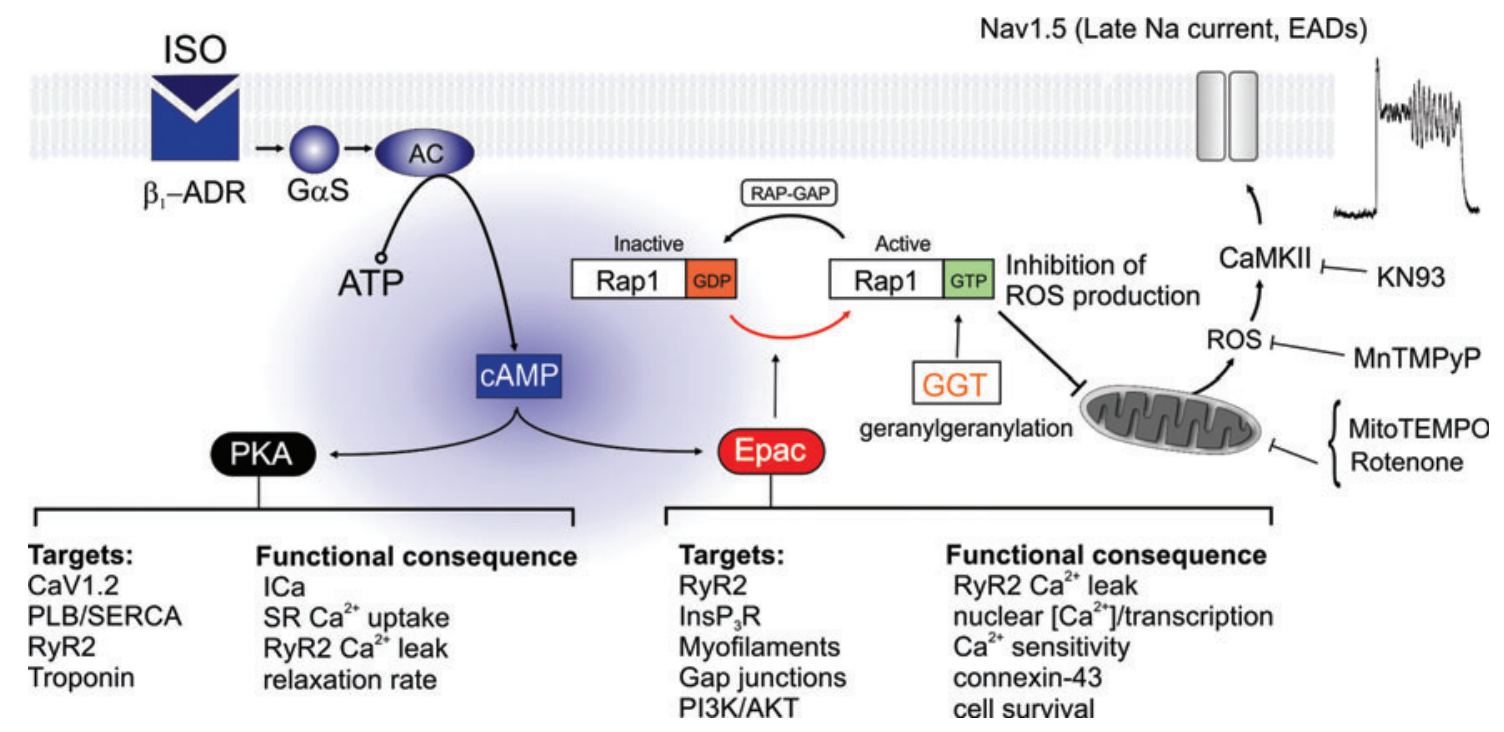

FIG. 8. Diagram summarizing $\beta_{1}$-adrenergic signaling via PKA and Epac-Rap1. The presence of a $\beta_{1}$-ADR agonist increases the production of cAMP via AC. cAMP acts simultaneously via both PKA and Epac pathways to influence the function of intracellular targets that control $\mathrm{Ca}^{2+}$ signaling, force production, electrical connectivity, and cell survival. Some effects of Epac are mediated via its role as a guanine nucleotide exchange factor for the small GTPase Rap1, which facilitates the release of guanosine diphosphate, thereby increasing the level of active Rap1 GTP. The GTPase-activating protein, RAPGAP, opposes this effect by facilitating GTP hydrolysis. Geranylgeranylation of active Rap1 via GGT-1 is required for interaction with downstream membrane targets. Our data suggest that Rap1GTP is a negative regulator of ROS production by the mitochondria. When Epac2 or GGT-1 is inhibited, the increase in ROS is associated with activation of CaMKII and the development of EAD arrhythmias due to increased $\mathrm{INa}_{\text {Late }}$ and AP prolongation. Arrhythmias can be prevented by inhibition of CaMKII with KN93, preincubation with the mitochondria-targeted antioxidant mitoTEMPO, or inhibition of INa Late with ranolazine. AC, adenylate cyclase; cAMP, cyclic adenosine monophosphate; PKA, protein kinase A; ROS, reactive oxygen species. To see this illustration in color, the reader is referred to the web version of this article at www.liebertpub.com/ars

and RyR2, which could only occur if Epac1 was widely expressed throughout the cells (28).

These authors suggested that the discrepancy might reflect the differing genetic backgrounds used in the two models. However, if this is the case, broader interpretation of the data and extrapolation to other species may be inappropriate. Another factor when considering the long-term effects of impaired signaling via Epac2-Rap1 is that possible adaptations in knockout models may not occur if changes in expression arise in response to disease, which simultaneously induces other forms of cellular dysfunction.

\section{Epac and GGT-1 inhibitors as therapeutic agents}

The nonspecific Epac inhibitor, ESI-09, has recently been shown to suppress pancreatic cancer cell migration and invasion and such drugs are being investigated for clinical use (2). In addition, there is a long-standing interest in the use of combined farnesyltransferase (FT) and GGT-1 inhibitors or selective GGT-1 inhibitors for the treatment of cancer (4).

Interestingly, preclinical animal studies on a range of combined inhibitors and selective GGT-1 inhibitors described a toxic effect in mice and dogs, leading to sudden death (21). Although the cause of death was not established, the toxic effects correlated with GGT-1 inhibition and the level of geranylated Rap1GTP, but not protein farnesylation. The authors concluded that the potential clinical benefit of this class of drugs may be limited by a narrow therapeutic index. Consistent with this, clinical trials on the combined FT/GGT-1 inhibitor L-778123 were hampered by cardiotoxic effects, including QT prolongation, arrhythmias, and syncope (47), which ultimately led to discontinuation of the drug.

The present study demonstrates that both GGT-1 inhibition and Epac2 inhibition can have lethal cardiotoxic effects in vivo (Fig. 7). Importantly, however, it is also shown that coadministration of the $1 \mathrm{Na}_{\text {late }}$ inhibitor, ranolazine, can block the proarrhythmic effects of Epac2 or GGT-1 inhibitors (Figs. 35). This might enable the cardiotoxic effects to be prevented, while allowing the drugs to be used at higher and more effective concentrations in the treatment of cancer, cardiovascular disease, or other pathological conditions where Rap1 signaling has a key role.

\section{Specificity of Epac2 and GGT-1 inhibitors}

While ESI-05 has been extensively validated as a selective Epac2 inhibitor (35), it is possible that the drug has other offtarget effects, which explain its proarrhythmic activity. However, this seems unlikely because the Epac2 inhibitor, HJC0350, had the same effects of ESI-05, and the structurally dissimilar GGT-1 inhibitors, GGTI-298 and GGTI-2147, which act at a different point on the Epac-Rap1 signaling pathway, have identical effects to Epac2 inhibition. Direct drug modulation of sarcolemmal ion channels seems unlikely because AP prolongation, activation of $\mathrm{INa}_{1 a t e}$, and induction of EADs were abolished by the mitochondria-targeted antioxidant, mitoTEMPO.

Inhibition of $\mathrm{hERG} / \mathrm{IKr}$ is a common cause of druginduced arrhythmias. However, hERG is weakly expressed in rat ventricle. Moreover, as ranolazine itself has a modest inhibitory effect on hERG, its ability to block the EADs 
induced by ESI-05 or GGTI-298 is not consistent with an arrhythmic mechanism involving hERG. It should be noted, however, ROS-dependent effects on hERG may be present in species (including humans) that do express the channel.

An increase in the L-type $\mathrm{Ca}^{2+}$ current can also predispose to EADs and previous studies have reported that ROS have direct and indirect effects on the channel, resulting in variable effects on ICa (43). However, ESI-05 or GGTI-298 had no significant effect on L-type $\mathrm{Ca}^{2+}$ current (Fig. 6A, B). The effects of ESI-05 or GGTI-298 are also unlikely to be caused by an indirect effect leading to a rise in [cAMP] because ISO did not induce EADs under the same conditions (not shown).

In summary, the present study identifies Epac2-Rap1 signaling as a novel feedback mechanism in the heart, which controls mitochondrial ROS production during simultaneous PKA activation. Any change (pathological or pharmacological) that reduces cAMP signaling via Epac-Rap1 relative to PKA will increase ROS and the probability of lifethreatening EAD arrhythmias. This mechanism may narrow the therapeutic index of drugs that target either Epac2 or GGT-1. However, the proarrhythmic effects can be ameliorated by inhibition of $\mathrm{INa}_{\text {late }}$, which blocks the EADs, while maintaining the other intracellular effects of Epac2 or Rap1 inhibition.

\section{Materials and Methods}

\section{Preparation of cells and solutions}

Wistar rats (150-200 g) were sacrificed in accordance with the UK Home Office Guidance on the Operation of Animals (Scientific Procedures) Act of 1986. ARVMs were isolated by collagenase digestion as described previously (61). ARVMs were perfused with solutions containing $(\mathrm{m} M) 113 \mathrm{NaCl} ; 5.4 \mathrm{KCl}$; $1 \mathrm{MgCl}_{2} ; 1.0 \mathrm{CaCl}_{2} ; 0.37 \mathrm{Na}_{2} \mathrm{HPO}_{4} ; 5.5$ glucose; and 5 HEPES, $20-22^{\circ} \mathrm{C}, \mathrm{pH}$ 7.1. Changes in intracellular calcium $\left(\left[\mathrm{Ca}^{2+}\right]_{\mathrm{i}}\right)$ were detected by loading myocytes with fluo-4 AM $(5 \mu M)$ for $15 \mathrm{~min}$ at room temperature $\left(20-22^{\circ} \mathrm{C}\right)$. A further $30 \mathrm{~min}$ was allowed for washout of fluo-4 AM and de-esterification.

Unless otherwise stated, all chemicals were obtained from Sigma Aldrich. The selective Epac2 inhibitors, ESI-05 (35, 50) and HJC0350 (14), were obtained from Biolog and Biotechne/Tocris, respectively. The GGT-1 inhibitor, GGTI-298 (22), is the ester prodrug form of the parent compound GGTI297 and both were obtained from Bio-techne/Tocris. In some experiments, GGTI-297 was introduced via a patch pipette during whole-cell patch-clamp recording, while GGTI-298 was added via the bathing solution. The GGT-1 inhibitor, GGTI-2147, was obtained from Calbiochem. Active Rap1 pull-down and detection kits were obtained from ThermoFisher Scientific.

\section{Confocal imaging}

The experimental chamber was placed on the stage of a Nikon Diaphot Eclipse TE2000 inverted microscope and ARVMs viewed using a $60 \mathrm{X}$ water immersion lens (Plan Apo, NA 1.2). Cells were imaged in line-scan mode using a Bio-Rad, Microradiance 2000 confocal laser scanning unit. Fluo-4 was excited at $488 \mathrm{~nm}$ and emitted fluorescence measured at $>515$. For ROS measurements, ARVMs were loaded with MitoSOX (5 $\mu \mathrm{m}$; Calbiochem) or CM-H${ }_{2} \mathrm{DCFDA}$ for $30 \mathrm{~min}$ at room temperature. By virtue of its localization, the mitoSOX signal is assumed to predominantly indicate superoxide.

There are known technical challenges and limitations associated with the measurement of ROS using dyes, such as mitoSOX or CM-H2DCFDA, in relation to specificity, photoactivation, and bleaching (56). To minimize some of these potential issues, the $20 \mathrm{~mW}$ laser excitation was markedly attenuated by $97-99 \%$, the experiments were as brief as possible (10-20 min), only 3-5 xy frames were collected in each run, and suitable time controls were done for each protocol. Furthermore, we have only drawn qualitative conclusions about changes in ROS production.

Expression of mito-roGFP2 or mitycam in ventricular myocytes involved exposing the cells to the virus (MOI 300-400) for $48 \mathrm{~h}$ under cell culture conditions as previously described (60). Cells were then imaged using confocal microscopy at $488 \mathrm{~nm}$ excitation and a bandpass emission of 515-530 nm.

During imaging experiments, cells were field stimulated via platinum wire electrodes ( $0.2 \mathrm{~mm}$ diameter; Goodfellow metals) positioned in parallel within a low-volume cell bath (61) using a Grass S48 stimulator. Square wave pulses of $6 \mathrm{~ms}$ duration were delivered at 1.5 times the threshold voltage for an electrically evoked contraction. Cells were only used if they responded consistently to each electrical stimulation and showed no signs of spontaneous activity under control conditions.

Image analysis was done using ImageJ and the Sparkmaster plug-in, which allows automatic detection of $\mathrm{Ca}^{2+}$ sparks. $\mathrm{Ca}^{2+}$ imaging data are presented as the mean \pm SEM and statistical significance was assessed using a $t$-test, chisquared test, or ANOVA as appropriate. Differences between means were considered significant at $p<0.05$.

\section{Measurement of cellular GSH/GSSg ratio in cardiac cells}

Experiments were done to measure the GSH/GSSG ratio in aliquots of cells using a luminescence-based system to detect and quantify GSH/GSSG ratios in ventricular cardiac cells (GSH/GSSG-Glo; Promega). This involves GSH-dependent conversion of the GSH probe, Luciferin-NT, to luciferin by a glutathione S-transferase enzyme coupled to the firefly luciferase reaction. Emitted light was measured from white-walled 96-well plates using a Promega Glomax system. App protocols were carried out according to the manufacturer's instructions.

\section{Experiments on HEK-293 cells}

During transfection, HEK-293 cells were placed in MEM (ThermoFisher Scientific) with siRNA for Rap1A (50 ng/ml; GE Healthcare Life Sciences/Dharmacon) and Rap1B (50 ng/ml; GE Healthcare Life Sciences/Dharmacon) or a scrambled sequence $(50 \mathrm{ng} / \mathrm{ml}$; AM4611, ThermoFisher Scientific), which acted as the control. After $7 \mathrm{~h}$, the medium was replaced with MEM supplemented with fetal bovine serum $(10 \%)$, pyruvate $(1 \%)$, NEAA $(1 \%)$, and Pen/Strep antibiotic (1\%). Cells were cultured for $48 \mathrm{~h}$ before use. Lipofectamine was used as the transfection reagent.

\section{Electrophysiology}

Whole-cell patch-clamp recordings were obtained in the voltage or current clamp mode using patch pipettes (resistance range $2-5 \mathrm{M} \Omega$ ). Stimulus protocols, recordings, and 
analysis were all performed with the use of an Axopatch 200B amplifier/Digidata 1322A interface controlled by pCLAMP 9.0 software (Molecular Devices). All experiments were carried out at $22^{\circ} \mathrm{C} \pm 1^{\circ} \mathrm{C}$.

$\mathrm{Na}^{+}$current recordings were made in voltage-clamp mode with myocytes held at a potential of $-80 \mathrm{mV}$. For L-type $\mathrm{Ca}^{2+}$ current measurement, cells were voltage-clamped at $-80 \mathrm{mV}$ and a $50-\mathrm{ms}$ prepulse to $-30 \mathrm{mV}$ was applied immediately before each test pulse to inactivate $\mathrm{Na}^{+}$and T-type $\mathrm{Ca}^{2+}$ channels, as previously described (44).

L-type currents were then activated by successive depolarizations to $+10 \mathrm{mV}$ (75-ms duration, $0.1 \mathrm{~Hz}$ ). Patch electrodes contained $(\mathrm{m} M) \mathrm{CsCl} 115$, HEPES 10, EGTA 10, tetraethylammonium chloride 20, MgATP 5, Tris-GTP 0.1 , and $\mathrm{CaCl}_{2} 1 ; \mathrm{pH}$ 7.05. The perfusate contained $(\mathrm{m} M) \mathrm{NaCl}$ 140, $\mathrm{CsCl} 5.4, \mathrm{CaCl}_{2} 2.5, \mathrm{MgCl}_{2}$ 0.5, HEPES 5.5, and glucose 11 ; $\mathrm{pH} 7.4$. $\mathrm{Na}^{+}$currents were evoked by a $200 \mathrm{~ms}$ step to $30 \mathrm{mV}$ and current signals sampled at $50 \mathrm{kHz}$ after low-pass filtering at $20 \mathrm{kHz}$. Series resistance compensation (typically 60-80\%) was applied and $\mathrm{INa}_{1 \text { ate }}$ was measured between 150 and $200 \mathrm{~ms}$ after initiation of the depolarizing step. If a significant increase $(>20 \%)$ in series resistance occurred, the experiment was terminated.

APs were recorded in current clamp mode and were evoked by $10 \mathrm{~ms}$ depolarizing current pulses applied every $10 \mathrm{~s}$. For these recordings, patch electrodes contained $(\mathrm{m} M)$ $\mathrm{KCl} 130, \mathrm{NaCl} 10$, EGTA 5, HEPES 5, MgATP 5, $\mathrm{CaCl}_{2} 1$, and $\mathrm{MgCl}_{2}$ 1; $\mathrm{pH}$ 7.2. The perfusate contained $(\mathrm{m} M) \mathrm{NaCl}$ 120, $\mathrm{KCl} 5, \mathrm{CaCl}_{2} 2, \mathrm{MgCl}_{2}$ 1, HEPES 10, and glucose 10; $\mathrm{pH}$ 7.4. AP duration (APD) was measured from the beginning of depolarization to the time when $25 \%\left(\mathrm{APD}_{0.25}\right), 50 \%$ $\left(\mathrm{APD}_{0.5}\right)$, and $90 \%\left(\mathrm{APD}_{0.9}\right)$ of repolarization was completed. Results are presented as mean \pm SEM, and statistical analysis was performed using unpaired Student's $t$-tests where $p<0.05$ was considered statistically significant.

\section{In vivo arrhythmic susceptibility to ESI-05 or GGTI-298}

Male Wistar rats ( 7 weeks old, $250 \mathrm{~g}$ ) were equipped with telemetric transmitters (CAF40; Data Sciences International) implanted under general anesthesia (Aerane, $2.5 \%$ in $\mathrm{O}_{2}$ ). All investigations conformed to the Position of the American Heart Association on Research Animal Use and European directives (2010/63/UE) and were approved by the institutional Animal Research Committee.

After allowing 10 days for full recovery and acclimatization, animals were randomly assigned to three groups. Seven rats were injected with ISO hydrochloride to induce submaximal activation of the adrenergic signaling pathway (Calbiochem, $1 \mathrm{mg} / \mathrm{kg}$ ip., in sterile $\mathrm{NaCl} \mathrm{0.9 \% ,} \mathrm{Baxter),} \mathrm{and}$ then injected with DMSO/NaCl solution (1/1000: v/v) as control for vehicle $5 \mathrm{~min}$ later. Seven rats received ESI-05 (BioLog, $1 \mathrm{mg} / \mathrm{kg}$ ip., in DMSO/NaCl solution, 1/1000: v/v) $5 \mathrm{~min}$ after injection of ISO hydrochloride $(1 \mathrm{mg} / \mathrm{kg}$ ip., in $\mathrm{NaCl}$ vehicle). Five rats were injected with GGTI 298 (Tocris, $1 \mathrm{mg} / \mathrm{kg}$ in $\mathrm{DMSO} / \mathrm{NaCl}$ solution, 1/1000: v/v) $5 \mathrm{~min}$ after injection of ISO hydrochloride ( $1 \mathrm{mg} / \mathrm{kg}$ ip., in $\mathrm{NaCl}$ vehicle).

All injections were performed at the same time slot. ECGs were recorded continuously throughout the experiments during baseline conditions, after ISO injection, and after either vehicle, ESI-05 or GGTI-298, administration, using a signal transmitter-receiver (RPC-1; Data Sciences International) connected to a data acquisition system (Ponemah Physiology Platform Pro, DSI) at a sampling rate of $2 \mathrm{kHz}$. ECGs were analyzed with ECG analysis module of Ponemah v5.2 software.

Heart rate was measured under baseline conditions and after injections. The ventricular ectopic beats were identified and counted by hand during the first $180 \mathrm{~min}$ of vehicle, ESI-05, or GGTI-298 injection. The occurrence of sustained ventricular tachycardia and sudden cardiac death was noted during the same period. Statistical analysis was performed using Fisher's exact test, where $p<0.05$ was considered statistically significant.

\section{Acknowledgments}

The financial support of the British Heart Foundation, the Wellcome Trust, and the Fondation de France (Synaptocard project, $\mathrm{N}^{\circ} 2013-00038586$ ) is acknowledged. The authors thank Professor Rao Sivaprasadarao for assistance with design of the siRNA experiments, Professor Godfrey Smith and Dr. Lyron Boyman for providing adenoviral mitycam, and Dr. Paul Schumacker for providing adenoviral mito-roGFP.

\section{Author Disclosure Statement}

The authors declare that they have no conflicts of interest.

\section{References}

1. Ackema KB, Hench J, Bockler S, Wang SC, Sauder U, Mergentaler H, Westermann B, Bard F, Frank S, and Spang A. The small GTPase Arf1 modulates mitochondrial morphology and function. EMBO J 33: 2659-2675, 2014.

2. Almahariq M, Tsalkova T, Mei FC, Chen H, Zhou J, Sastry SK, Schwede F, and Cheng X. A novel EPAC-specific inhibitor suppresses pancreatic cancer cell migration and invasion. Mol Pharmacol 83: 122-128, 2013.

3. Andersson DC, Fauconnier J, Yamada T, Lacampagne A, Zhang SJ, Katz A, and Westerblad H. Mitochondrial production of reactive oxygen species contributes to the betaadrenergic stimulation of mouse cardiomycytes. J Physiol 589: 1791-1801, 2011.

4. Appels NM, Beijnen JH, and Schellens JH. Development of farnesyl transferase inhibitors: a review. Oncologist 10: 565-578, 2005.

5. Baker AJ. Adrenergic signaling in heart failure: a balance of toxic and protective effects. Pflugers Arch 466: 11391150, 2014.

6. Chotani MA, Bauer JA, Joshi MS, and Jeyaraj SC. Rap1a as a marker for cardiac arrhythmia. US20120301402 A1. 29-11-2012. USA, Google Patents.

7. Cloughesy TF, Kuhn J, Robins HI, Abrey L, Wen P, Fink K, Lieberman FS, Mehta M, Chang S, Yung A, DeAngelis L, Schiff D, Junck L, Groves M, Paquette S, Wright J, Lamborn K, Sebti SM, and Prados M. Phase I trial of tipifarnib in patients with recurrent malignant glioma taking enzymeinducing antiepileptic drugs: a North American Brain Tumor Consortium Study. J Clin Oncol 23: 6647-6656, 2005.

8. Covian R and Balaban RS. Cardiac mitochondrial matrix and respiratory complex protein phosphorylation. Am J Physiol Heart Circ Physiol 303: H940-H966, 2012.

9. Dai DF, Johnson SC, Villarin JJ, Chin MT, Nieves-Cintron M, Chen T, Marcinek DJ, Dorn GW, Kang YJ, Prolla TA, Santana LF, and Rabinovitch PS. Mitochondrial oxidative stress mediates angiotensin II-induced cardiac hypertrophy and Galphaq overexpression-induced heart failure. Circ Res 108: 837-846, 2011. 
10. Di Benedetto G, Pendin D, Greotti E, Pizzo P, and Pozzan T. Ca2+ and cAMP cross-talk in mitochondria. $J$ Physiol 592: 305-312, 2014.

11. Ding B, Abe J, Wei H, Huang Q, Walsh RA, Molina CA, Zhao A, Sadoshima J, Blaxall BC, Berk BC, and Yan C. Functional role of phosphodiesterase 3 in cardiomyocyte apoptosis: implication in heart failure. Circulation 111: 2469-2476, 2005.

12. Finder JD, Litz JL, Blaskovich MA, McGuire TF, Qian Y, Hamilton AD, Davies P, and Sebti SM. Inhibition of protein geranylgeranylation causes a superinduction of nitricoxide synthase- 2 by interleukin-1beta in vascular smooth muscle cells. J Biol Chem 272: 13484-13488, 1997.

13. Fischmeister R, Castro LR, Abi-Gerges A, Rochais F, Jurevicius J, Leroy J, and Vandecasteele G. Compartmentation of cyclic nucleotide signaling in the heart: the role of cyclic nucleotide phosphodiesterases. Circ Res 99: 816828, 2006.

14. Han YS, Arroyo J, and Ogut O. Human heart failure is accompanied by altered protein kinase A subunit expression and post-translational state. Arch Biochem Biophys 538: 25-33, 2013.

15. Haviland S, Cleemann L, Kettlewell S, Smith GL, and Morad M. Diversity of mitochondrial $\mathrm{Ca}(2)(+)$ signaling in rat neonatal cardiomyocytes: evidence from a genetically directed $\mathrm{Ca}(2)(+)$ probe, mitycam-E31Q. Cell Calcium 56: 133-146, 2014.

16. Jeong EM, Liu M, Sturdy M, Gao G, Varghese ST, Sovari AA, and Dudley SC, Jr. Metabolic stress, reactive oxygen species, and arrhythmia. J Mol Cell Cardiol 52: 454-463, 2012.

17. Kim S, Mizoguchi A, Kikuchi A, and Takai Y. Tissue and subcellular distributions of the smg-21/rap1/Krev-1 proteins which are partly distinct from those of c-ras p21 s. Mol Cell Biol 10: 2645-2652, 1990.

18. Kirchhefer U, Schmitz W, Scholz H, and Neumann J. Activity of cAMP-dependent protein kinase and $\mathrm{Ca} 2+/$ calmodulin-dependent protein kinase in failing and nonfailing human hearts. Cardiovasc Res 42: 254-261, 1999.

19. Lehnart SE and Marks AR. Phosphodiesterase 4D and heart failure: a cautionary tale. Expert Opin Ther Targets 10: 677-688, 2006.

20. Lehnart SE, Wehrens XH, Reiken S, Warrier S, Belevych AE, Harvey RD, Richter W, Jin SL, Conti M, and Marks AR. Phosphodiesterase 4D deficiency in the ryanodinereceptor complex promotes heart failure and arrhythmias. Cell 123: 25-35, 2005.

21. Lobell RB, Omer CA, Abrams MT, Bhimnathwala HG, Brucker MJ, Buser CA, Davide JP, deSolms SJ, Dinsmore CJ, Ellis-Hutchings MS, Kral AM, Liu D, Lumma WC, Machotka SV, Rands E, Williams TM, Graham SL, Hartman GD, Oliff AI, Heimbrook DC, and Kohl NE. Evaluation of farnesyl: protein transferase and geranylgeranyl: protein transferase inhibitor combinations in preclinical models. Cancer Res 61: 8758-8768, 2001.

22. McGuire TF, Qian Y, Vogt A, Hamilton AD, and Sebti SM. Platelet-derived growth factor receptor tyrosine phosphorylation requires protein geranylgeranylation but not farnesylation. J Biol Chem 271: 27402-27407, 1996.

23. Metrich M, Laurent AC, Breckler M, Duquesnes N, Hmitou I, Courillau D, Blondeau JP, Crozatier B, Lezoualc'h F, and Morel E. Epac activation induces histone deacetylase nuclear export via a Ras-dependent signalling pathway. Cell Signal 22: 1459-1468, 2010.
24. Metrich M, Lucas A, Gastineau M, Samuel JL, Heymes C, Morel E, and Lezoualc'h F. Epac mediates beta-adrenergic receptor-induced cardiomyocyte hypertrophy. Circ Res 102: 959-965, 2008.

25. Morel E, Marcantoni A, Gastineau M, Birkedal R, Rochais F, Garnier A, Lompre AM, Vandecasteele G, and Lezoualc'h F. cAMP-binding protein Epac induces cardiomyocyte hypertrophy. Circ Res 97: 1296-1304, 2005.

26. Oestreich EA, Malik S, Goonasekera SA, Blaxall BC, Kelley GG, Dirksen RT, and Smrcka AV. Epac and phospholipase Cepsilon regulate $\mathrm{Ca} 2+$ release in the heart by activation of protein kinase Cepsilon and calciumcalmodulin kinase II. J Biol Chem 284: 1514-1522, 2009.

27. Oestreich EA, Wang H, Malik S, Kaproth-Joslin KA, Blaxall BC, Kelley GG, Dirksen RT, and Smrcka AV. Epac-mediated activation of phospholipase C(epsilon) plays a critical role in beta-adrenergic receptor-dependent enhancement of $\mathrm{Ca} 2+$ mobilization in cardiac myocytes. $J$ Biol Chem 282: 5488-5495, 2007.

28. Okumura S, Fujita T, Cai W, Jin M, Namekata I, Mototani Y, Jin H, Ohnuki Y, Tsuneoka Y, Kurotani R, Suita K, Kawakami Y, Hamaguchi S, Abe T, Kiyonari H, Tsunematsu T, Bai Y, Suzuki S, Hidaka Y, Umemura M, Ichikawa Y, Yokoyama U, Sato M, Ishikawa F, IzumiNakaseko H, Adachi-Akahane S, Tanaka H, and Ishikawa Y. Epac1-dependent phospholamban phosphorylation mediates the cardiac response to stresses. J Clin Invest 124: 2785-2801, 2014.

29. Osadchii OE. Myocardial phosphodiesterases and regulation of cardiac contractility in health and cardiac disease. Cardiovasc Drugs Ther 21: 171-194, 2007.

30. Packer M. Neurohormonal interactions and adaptations in congestive heart failure. Circulation 77: 721-730, 1988.

31. Parks RJ and Howlett SE. H-89 decreases the gain of excitation-contraction coupling and attenuates calcium sparks in the absence of beta-adrenergic stimulation. Eur J Pharmacol 691: 163-172, 2012.

32. Parnell E, Palmer TM, and Yarwood SJ. The future of EPAC-targeted therapies: agonism versus antagonism. Trends Pharmacol Sci 36: 203-214, 2015.

33. Pereira L, Rehmann H, Lao DH, Erickson JR, Bossuyt J, Chen J, and Bers DM. Novel Epac fluorescent ligand reveals distinct Epac1 vs. Epac2 distribution and function in cardiomyocytes. Proc Natl Acad Sci U S A 112: 39913996, 2015.

34. Pereira L, Ruiz-Hurtado G, Morel E, Laurent AC, Metrich M, Dominguez-Rodriguez A, Lauton-Santos S, Lucas A, Benitah JP, Bers DM, Lezoualc'h F, and Gomez AM. Epac enhances excitation-transcription coupling in cardiac myocytes. J Mol Cell Cardiol 52: 283-291, 2012.

35. Rehmann H. Epac-inhibitors: facts and artefacts. Sci Rep 3: 3032, 2013.

36. Reiken S, Wehrens XH, Vest JA, Barbone A, Klotz S, Mancini D, Burkhoff D, and Marks AR. Beta-blockers restore calcium release channel function and improve cardiac muscle performance in human heart failure. Circulation 107: 2459-2466, 2003.

37. Remans PH, Gringhuis SI, van Laar JM, Sanders ME, Papendrecht-van der Voort EA, Zwartkruis FJ, Levarht EW, Rosas M, Coffer PJ, Breedveld FC, Bos JL, Tak PP, Verweij CL, and Reedquist KA. Rap1 signaling is required for suppression of Ras-generated reactive oxygen species and protection against oxidative stress in T lymphocytes. $J$ Immunol 173: 920-931, 2004. 
38. Remans PH, Wijbrandts CA, Sanders ME, Toes RE, Breedveld FC, Tak PP, van Laar JM, and Reedquist KA. CTLA-4IG suppresses reactive oxygen species by preventing synovial adherent cell-induced inactivation of Rap1, a Ras family GTPASE mediator of oxidative stress in rheumatoid arthritis T cells. Arthritis Rheum 54: 31353143, 2006.

39. Remondino A, Kwon SH, Communal C, Pimentel DR, Sawyer DB, Singh K, and Colucci WS. Beta-adrenergic receptor-stimulated apoptosis in cardiac myocytes is mediated by reactive oxygen species/c-Jun NH2-terminal kinase-dependent activation of the mitochondrial pathway. Circ Res 92: 136-138, 2003.

40. Rokita AG and Anderson ME. New therapeutic targets in cardiology: arrhythmias and $\mathrm{Ca} 2+/$ calmodulin-dependent kinase II (CaMKII). Circulation 126: 2125-2139, 2012.

41. Rosca MG and Hoppel CL. Mitochondria in heart failure. Cardiovasc Res 88: 40-50, 2010.

42. Rosca MG, Vazquez EJ, Kerner J, Parland W, Chandler MP, Stanley W, Sabbah HN, and Hoppel CL. Cardiac mitochondria in heart failure: decrease in respirasomes and oxidative phosphorylation. Cardiovasc Res 80: 30-39, 2008.

43. Sag CM, Wagner S, and Maier LS. Role of oxidants on calcium and sodium movement in healthy and diseased cardiac myocytes. Free Radic Biol Med 63: 338-349, 2013.

44. Scragg JL, Dallas ML, Wilkinson JA, Varadi G, and Peers C. Carbon monoxide inhibits L-type $\mathrm{Ca} 2+$ channels via redox modulation of key cysteine residues by mitochondrial reactive oxygen species. J Biol Chem 283: 2441224419, 2008.

45. Somekawa S, Fukuhara S, Nakaoka Y, Fujita H, Saito Y, and Mochizuki N. Enhanced functional gap junction neoformation by protein kinase A-dependent and Epacdependent signals downstream of cAMP in cardiac myocytes. Circ Res 97: 655-662, 2005.

46. Stokman G, Qin Y, Booij TH, Ramaiahgari S, Lacombe M, Dolman ME, van Dorenmalen KM, Teske GJ, Florquin S, Schwede F, van de WB, Kok RJ, and Price LS. Epac-Rap Signaling Reduces Oxidative Stress in the Tubular Epithelium. J Am Soc Nephrol 25: 1474-1485, 2014.

47. Strevel EL, Ing DJ, and Siu LL. Molecularly targeted oncology therapeutics and prolongation of the QT interval. J Clin Oncol 25: 3362-3371, 2007.

48. Sun J, Ohkanda J, Coppola D, Yin H, Kothare M, Busciglio B, Hamilton AD, and Sebti SM. Geranylgeranyltransferase I inhibitor GGTI-2154 induces breast carcinoma apoptosis and tumor regression in H-Ras transgenic mice. Cancer Res 63: 8922-8929, 2003.

49. Thomson M. What are guanosine triphosphate-binding proteins doing in mitochondria? Biochim Biophys Acta 1403: 211-218, 1998.

50. Tsalkova T, Mei FC, Li S, Chepurny OG, Leech CA, Liu T, Holz GG, Woods VL, Jr., and Cheng X. Isoform-specific antagonists of exchange proteins directly activated by cAMP. Proc Natl Acad Sci U S A 109: 18613-18618, 2012.

51. Ulucan C, Wang X, Baljinnyam E, Bai Y, Okumura S, Sato M, Minamisawa S, Hirotani S, and Ishikawa Y. Developmental changes in gene expression of Epac and its upregulation in myocardial hypertrophy. Am J Physiol Heart Circ Physiol 293: H1662-H1672, 2007.

52. Valsecchi F, Ramos-Espiritu LS, Buck J, Levin LR, and Manfredi G. cAMP and mitochondria. Physiology (Bethesda) 28: 199-209, 2013.
53. Wagner S, Dantz C, Flebbe H, Azizian A, Sag CM, Engels S, Mollencamp J, Dybkova N, Islam T, Shah AM, and Maier LS. NADPH oxidase 2 mediates angiotensin IIdependent cellular arrhythmias via PKA and CaMKII. $J$ Mol Cell Cardiol 75: 206-215, 2014.

54. Wang H, Jiang Y, Shi D, Quilliam LA, ChrzanowskaWodnicka M, Wittchen ES, Li DY, and Hartnett ME. Activation of Rap1 inhibits NADPH oxidase-dependent ROS generation in retinal pigment epithelium and reduces choroidal neovascularization. FASEB J 28: 265-274, 2014.

55. Wang J, Liu X, Arneja AS, and Dhalla NS. Alterations in protein kinase $\mathrm{A}$ and protein kinase $\mathrm{C}$ levels in heart failure due to genetic cardiomyopathy. Can J Cardiol 15: 683690, 1999.

56. Wang X, Fang H, Huang Z, Shang W, Hou T, Cheng A, and Cheng $\mathrm{H}$. Imaging ROS signaling in cells and animals. J Mol Med (Berl) 91: 917-927, 2013.

57. Xiao L, Zhu X, Yang S, Liu F, Zhou Z, Zhan M, Xie P, Zhang D, Li J, Song P, Kanwar YS, and Sun L. Rap1 ameliorates renal tubular injury in diabetic nephropathy. Diabetes 63: 1366-1380, 2014.

58. Xie LH, Chen F, Karagueuzian HS, and Weiss JN. Oxidative-stress-induced afterdepolarizations and calmodulin kinase II signaling. Circ Res 104: 79-86, 2009.

59. Yan C, Miller CL, and Abe J. Regulation of phosphodiesterase 3 and inducible cAMP early repressor in the heart. Circ Res 100: 489-501, 2007.

60. Yang Z, Kirton HM, Macdougall DA, Boyle JP, Deuchars J, Frater B, Ponnambalam S, Hardy ME, White E, Calaghan SC, Peers C, and Steele DS. The Golgi apparatus is a functionally distinct $\mathrm{Ca} 2+$ store regulated by the PKA and Epac branches of the beta1-adrenergic signaling pathway. Sci Signal 8: ra101, 2015.

61. Yang Z and Steele DS. Effects of cytosolic ATP on spontaneous and triggered $\mathrm{Ca} 2+$-induced $\mathrm{Ca} 2+$ release in permeabilised rat ventricular myocytes. J Physiol $523 \mathrm{Pt} 1$ : 29-44, 2000.

62. Zhao Z, Fefelova N, Shanmugam M, Bishara P, Babu GJ, and Xie LH. Angiotensin II induces afterdepolarizations via reactive oxygen species and calmodulin kinase II signaling. J Mol Cell Cardiol 50: 128-136, 2011.

63. Zorov DB, Filburn CR, Klotz LO, Zweier JL, and Sollott SJ. Reactive oxygen species (ROS)-induced ROS release: a new phenomenon accompanying induction of the mitochondrial permeability transition in cardiac myocytes. $J$ Exp Med 192: 1001-1014, 2000.

Address correspondence to: Prof. Derek S. Steele Faculty of Biological Sciences School of Biomedical Sciences

(Garstang Building 7.53)

University of Leeds Woodhouse Lane Leeds LS29JT

United Kingdom

E-mail: d.steele@leeds.ac.uk

Date of first submission to ARS Central, August 28, 2015; date of final revised submission, September 19, 2016; date of acceptance, September 19, 2016. 


$\begin{aligned} & \quad \text { Abbreviations Used } \\ & \beta_{1}-\mathrm{AD}=\beta_{1} \text {-adrenergic } \\ & \beta_{1}-\mathrm{ADR}=\beta_{1} \text {-adrenoceptor } \\ & {\left[\mathrm{Ca}^{2+}\right]_{\mathrm{i}} }=\text { intracellular calcium } \\ & \mathrm{AP}=\text { action potential } \\ & \mathrm{ARVMs}=\text { adult rat ventricular myocytes } \\ & \mathrm{CaMKII}=\mathrm{Ca}^{2+} / \text { calmodulin-dependent kinase II } \\ & \mathrm{cAMP}=\mathrm{cyclic} \text { adenosine monophosphate } \\ & \mathrm{DPI}=\text { diphenyleneiodonium } \\ & \mathrm{DTT}=\text { dithiothreitol } \\ & \mathrm{EADs}=\text { early afterdepolarization arrhythmias }\end{aligned}$

$\begin{aligned} \text { ECG } & =\text { electrocardiogram } \\ \text { Epac } & =\text { exchange protein directly activated } \\ & \quad \text { by cAMP } \\ \mathrm{GGT}-1 & =\text { geranylgeranyltransferase-1 } \\ \mathrm{HF} & =\text { heart failure } \\ \mathrm{INa} \mathrm{a}_{\text {late }} & =\text { late Na current } \\ \mathrm{ISO} & =\text { isoproterenol } \\ \mathrm{MOI} & =\text { multiplicity of infection } \\ \mathrm{PKA} & =\text { protein kinase } \mathrm{A} \\ \mathrm{PLC} \xi & =\text { phospholipase-C epsilon } \\ \mathrm{ROS} & =\text { reactive oxygen species } \\ \mathrm{RyR} 2 & =\text { type-2 ryanodine receptor }\end{aligned}$

